\title{
Economía social y desarrollo local/rural. Un análisis de sus sinergias
}

\author{
JUAN JOSÉ JUSTE CARRIÓN \\ Departamento de Economía Aplicada, UNIVERSIDAD DE VALLADOLID, ESPAÑA. E- \\ mail: juste@eco.uva.es
}

JESÚS MARÍA GÓMEZ GARCÍA

Departamento de Economía Aplicada, UNIVERSIDAD DE VALLADOLID, ESPAÑA. Email:jmgomez@eco.uva.es

\author{
JOSEFA EUGENIA FERNÁNDEZ ARUFE \\ Departamento de Economía Aplicada, UNIVERSIDAD DE VALLADOLID, ESPAÑA. E- \\ mail: jfarufe@eco.uva.es
}

\begin{abstract}
RESUMEN
Los procesos de desarrollo local/rural requieren la concurrencia en el territorio de factores muy diversos (económicos, sociales, culturales, etc.), así como de un considerable esfuerzo de cohesión económica y social en el que deben implicarse las fuerzas vivas del territorio, entre las cuales se encuentran las empresas de la Economía Social. El objetivo de este trabajo es analizar la relevancia del subsector empresarial de la Economía Social en el proceso de desarrollo local en Castilla y León, con especial referencia al mundo rural. De acuerdo con ello, partiendo de la identificación de los aspectos fundamentales que caracterizan el desarrollo local como elemento de reestructuración productiva (origen, factores condicionantes y espacios productivos típicos), en el trabajo se describen sus vínculos con el sector de la Economía Social. A continuación, se analiza, desde una perspectiva aplicada, la contribución de las empresas de la Economía Social al desarrollo endógeno local/rural de Castilla y León en términos de empleo y producción. Los datos requeridos para llevar a cabo este análisis proceden, además de las fuentes estadísticas oficiales, de los resultados de una encuesta propia realizada a las empresas de la Economía Social en Castilla y León.

Palabras clave: Economía social, Desarrollo local/rural, Empresas de economía social.
\end{abstract}

\section{Social Economy and Local/Rural Development. An analysis of synergies}

\begin{abstract}
Local/rural development processes require the presence in the territory of many different factors (economic, social, cultural, etc.) as well as a considerable economic and social cohesion in which should be engaged the forces of the territory, among which are the enterprises of the Social Economy. The aim of this paper is to analyze the relevance of the business sector of the Social Economy in the process of local development in Castilla y León, with special reference to rural areas. Accordingly, based on the identification of the fundamental aspects that characterize the development as part of economic restructuring (origin, production factors and spaces typical), the paper describes its links with the Social Economy sector. Later, it analyzes, from an applied perspective, the contribution of the Social Economy enterprises to local/rural endogenous development of Castilla y León in terms of employment and production. The data to conduct this analysis is based, in addition to those obtained from the official statistical sources, on the results of a own survey conducted to the Social Economy enterprises in Castilla y León.
\end{abstract}

Keywords: Social economy, Local/Rural development, Social economy enterprises.

Clasificación JEL: O18, P13, R10, R50, L20

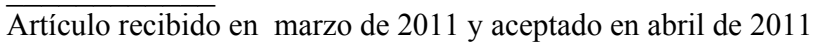

Artículo disponible en versión electrónica en la página www.revista-eea.net, ref. ə-29110 


\section{INTRODUCCIÓN}

Los procesos de desarrollo local/rural requieren la concurrencia en el territorio de factores muy diversos (económicos, sociales, culturales, etc.), así como de un considerable esfuerzo de cohesión económica y social en el que deben implicarse las fuerzas vivas del territorio, entre las cuales se encuentran las empresas de la Economía Social. En este sentido, diversos estudios a escala nacional e internacional han puesto de manifiesto que dichas entidades, tanto a través de sus principales formas empresariales tradicionales (las cooperativas) como mediante otras nuevas surgidas para dar respuesta a problemas más específicos (las sociedades laborales, los centros especiales de empleo, etc.), han venido demostrando una elevada capacidad para sostener e impulsar actividades económicas, contribuyendo al desarrollo económico territorial a nivel local/rural través de la dinamización de los recursos endógenos, del fomento de la cultura empresarial emprendedora y de su capacidad para satisfacer las necesidades sociales y económicas del territorio ${ }^{1}$. Estas cualidades adquieren especial trascendencia en las zonas rurales, cuyas especificidades demográficas (escasa densidad, elevado grado de envejecimiento poblacional, etc.) y también productivas (primacía de las actividades agrarias, bajo nivel de diversificación, etc.) hacen necesario estimular e intensificar las iniciativas generadoras de empleo y riqueza, constituyendo la Economía Social un sector con grandes potencialidades para el desarrollo económico en el ámbito local/rural.

El principal objetivo de este trabajo es poner de relieve la relevancia del subsector empresarial de la Economía Social en el proceso de desarrollo local en Castilla y León, con especial referencia al medio rural. De acuerdo con ello, partiendo de la identificación de los aspectos fundamentales que caracterizan el desarrollo local como elemento de reestructuración productiva (origen, factores condicionantes y espacios productivos típicos), en los apartados siguientes se van mostrando los importantes vínculos que presenta con el sector de la Economía Social. A continuación, se analiza, desde una perspectiva aplicada, las posibles sinergias existentes entre las empresas de la Economía Social y los procesos de desarrollo endógeno en el ámbito local/rural de Castilla y León, tanto en términos de empleo como de producción. Los datos para llevar a cabo este análisis proceden, además de las tradicionales fuentes estadísticas oficiales, de los resultados obtenidos de una encuesta propia realizada a las empresas de la Economía Social en Castilla y León ${ }^{2}$.

\footnotetext{
${ }^{1}$ Véanse, en este sentido, los estudios de Lévesque, (1999), Barea y Monzón (2002), Martignetti (2002), Tremblay et al. (2002), Demoustier (2005), Salinas et al. (2005) y De Pablo y Uribe (2009), entre otros.

${ }^{2}$ Dicha encuesta se llevó a cabo en el marco de una investigación más amplia desarrollada por el Departamento de Economía Aplicada de la Universidad de Valladolid y cofinanciada por el
} 


\section{REESTRUCTURACIÓN PRODUCTIVA Y DESARROLLO LOCAL/RURAL}

La profunda reestructuración productiva subsiguiente a la crisis económica de los años 70 se ha traducido, a lo largo de los últimos treinta años, en una compleja reorganización de los espacios productivos en las economías occidentales, de la que ha resultado un variopinto puzzle de regiones y localidades, interpretable en términos de ganadores $(+)$ y perdedores $(-)$ y cuyas piezas fundamentales serían (Benko y Lipietz, 1992; Vázquez Barquero, 2005):

1. Zonas de antigua industrialización (-). Densamente pobladas y con predominio de sectores maduros sensibles a los costes laborales y energéticos (textil, siderurgia, minería...). Duramente castigadas por la crisis y pasto de un acelerado proceso de ajuste empresarial, dominado por una lógica de desindustrialización y reconversión.

2. Áreas rurales deprimidas (-). Eminentemente agrarias, en riesgo de descapitalización y poco atractivas para la actividad industrial y terciaria. Al desempleo y al éxodo y envejecimiento demográficos, se añaden la concentración de las explotaciones; la creciente dependencia de las grandes firmas industriales y de distribución; el bajo nivel de vida; la escasez de infraestructuras y servicios; el abandono y degradación del territorio; o la falta de oportunidades.

3. Áreas urbanas de tejido económico reconvertido $(+)$. Protagonistas de una regeneración urbana basada en la revitalización económica y en la reutilización de terrenos degradados, resultantes del cierre de empresas y de la congestión y deterioro del entorno físico y del tejido económico. Son ciudades que han sabido reaccionar frente a la desconcentración industrial hacia la periferia, impulsando un nuevo papel metropolitano en los negocios, con los servicios como punta de lanza.

4. Espacios ligados a actividades estratégicas y a la innovación (+). Resultado de la aparición, en áreas específicas, de concentraciones tecnológicas planificadas, de la mano de la Administración Pública y/o de otras instituciones (universidades, asociaciones empresariales...), con objeto de promover el desarrollo regional, a través de la $\mathrm{I}+\mathrm{D}+\mathrm{i}$, la reindustrialización y la instalación de nuevas industrias en su seno. Figuran aquí las llamadas tecnópolis y los parques científicos y tecnológicos.

5. Espacios productivos emergentes $(+)$. Territorios con una trayectoria tecnológica de desarrollo difuso, consistente con la lógica de la acumulación flexible, donde niveles retributivos más bajos, escasa conflictividad laboral,

FSE (Proyecto 108/063872 FGUVA). Una síntesis de los resultados principales y de las conclusiones de dicha investigación se recoge en Fernández y Gómez (2008). 
accesibilidad a los mercados, entorno agradable, receptividad social, etc., constituyen fuentes de ventaja competitiva. Es el caso de muchas ciudades favorecidas por la descentralización productiva y la menor fricción de la distancia, y de otros espacios periféricos (ciudades medias y cabeceras de comarca rurales) sustentados autónomamente gracias a una amplia dotación de recursos locales.

Esta heterogénea geografía productiva parece reflejar, en los inicios del siglo XXI, más que la implantación de un nuevo y único patrón de desarrollo territorial postfordista, la coexistencia de una pluralidad limitada de modelos para la resolución de los problemas económicos. Una de sus posibles sendas, típica de los espacios emergentes, es la del desarrollo endógeno ${ }^{3}$, patrón organizativo flexible y descentralizado basado en la valorización y aprovechamiento de los recursos propios y en la versatilidad de las PYMES, y donde el territorio juega un papel activo como agente de desarrollo.

Las figuras en que se materializa dicho modelo de desarrollo desde abajo distritos industriales y, más en general, sistemas productivos locales (SPL) ${ }^{4}$ están detrás del éxito de numerosos territorios por la vía de la industrialización,

\footnotetext{
${ }^{3}$ Vázquez Barquero (1988) define el desarrollo endógeno en los siguientes términos: "un proceso de crecimiento económico y cambio estructural que conduce a una mejora del nivel de vida de la población local, en el que se pueden identificar, al menos, dos dimensiones: una económica, en la que los empresarios locales usan su capacidad para organizar los factores productivos locales con niveles de productividad suficiente para ser competitivos en los mercados; otra socio-cultural, en la que los valores y las instituciones locales sirven de base al proceso de desarrollo. La estrategia de desarrollo endógeno, no obstante, debe considerar una dimensión adicional, la político-administrativa, en la que las políticas territoriales permiten crear un entorno económico local favorable, protegerlo de las interferencias externas y favorecer e impulsar el desarrollo del potencial local".

${ }^{4}$ El distrito industrial constituye una categoría sui generis de SPL, basado en la presencia de un amplio contingente de PYMES locales especializadas. En general, entre los elementos económicos que suelen concurrir en todo SPL, como patrón de organización industrial, figuran: 1) Una elevada división del trabajo entre empresas (PYMES y/o grandes) radicadas en un mismo espacio geográfico, a escala intra e intersectorial, cuyo último eslabón sería el trabajo a domicilio y, en ocasiones, la economía sumergida, como exponente de flexibilidad laboral. 2) Una especialización productiva en empresas e instalaciones que facilita su modernización tecnológica y su relativa autonomía económica. 3) El juego combinado de mercado y reciprocidad (entendida ésta como intercambio gratuito y directo de información y servicios entre empresarios y proveedores, y vinculada a la fidelidad e identidad locales), que, por un lado, favorece la adquisición de conocimientos profesionales y experiencia y el acceso a mejoras tecnológicas y organizativas, y, por otro, genera el ambiente propicio para la asunción local de riesgo en los negocios, reforzando el potencial sinérgico de la comunidad. 4) La atmósfera de la industrialización difusa como trasfondo, ya que la fuerte interacción entre economía y sociedad y las iniciativas locales de desarrollo constituyen la base de su nacimiento y consolidación. Para mayor información sobre el concepto, la tipología y los rasgos de los SPL, véase Garofoli y Mazzoni (1994).
} 
apareciendo como una válvula de escape a la marginación para muchas áreas rurales.

Los elementos que concurren en dichos espacios productivos - explicativos de su singular dinamismo e integrantes de su potencial endógeno - son de muy diversa índole, destacando en particular los siguientes (Castillo et al., 1994):

a) Recursos humanos: un nivel de población suficiente, una amplia oferta de trabajo, flexible y con un notable grado de cualificación, y la presencia de emprendedores capaces de generar empleo y diversificar el tejido económico.

b) Recursos materiales: una amplia dotación de recursos naturales, una suficiente red de equipamientos e infraestructuras técnicas y sociales y un importante caudal de recursos económicos financieros: mecanismos de ahorro local, servicios financieros $\mathrm{y}$ un importante número de establecimientos productivos (especialmente PYMES).

c) Recursos técnicos: el conocimiento contextual y la receptividad al cambio tecnológico como fuente de creatividad local.

d) Recursos culturales: una escala de valores compartidos y una fuerte identidad local.

e) El poder y capacidad de organización a escala local, merced a la implicación de las fuerzas vivas del área: empresas y otros agentes privados (sindicatos, patronal, cámaras de comercio, bancos...), poderes públicos, formas sociales y económicas de solidaridad e integración (familias, cooperativismo, redes de ayuda, asociaciones ciudadanas...), e incluso estructuras de animación e información vitales en las zonas rurales (grupos de acción local, agentes de desarrollo local,...). Entre esa amplia diversidad de figuras se inscriben las que configuran la Economía Social.

\section{LA ECONOMÍA SOCIAL Y SUS VÍNCULOS CON EL DESARROLLO LOCAL/RURAL}

La noción de Economía Social presenta acepciones diversas que le confieren un carácter esencialmente abierto, a la vez que una cierta dosis de ambigüedad. En el ámbito científico, y en aras de reflejar su comportamiento y creciente importancia económica, la definición más operativa es la propuesta por el Centro Internacional de Investigación e Información sobre la Economía Pública Social y Cooperativa (CIRIEC-España) ${ }^{5}$ : "aquel conjunto de empresas privadas creadas para satisfacer las necesidades de sus socios a través del

\footnotetext{
${ }^{5}$ Para una revisión del alcance y contenido de esta definición, así como de otras visiones del concepto de Economía Social puede consultarse Barea y Monzón (2002), Chaves y Monzón (2003) y Chaves (2006).
} 
mercado, produciendo bienes y servicios, asegurando o financiando y en las que la distribución del beneficio y la toma de decisiones no están ligadas directamente con el capital aportado por cada socio, correspondiendo un voto a cada uno de ellos. La Economía Social también incluye a las instituciones sin fines de lucro que son productores no de mercado privados, no controlados por las Administraciones Públicas y que producen servicios no destinados a la venta para determinados grupos de hogares, procediendo sus recursos principales de contribuciones voluntarias efectuadas por los hogares en su calidad de consumidores, de pagos de las Administraciones Públicas y de rentas de la propiedad".

A la luz de dicha definición, cabe distinguir dos subsectores dentro de la Economía Social: el de mercado o empresarial y el de no mercado o sin ánimo de lucro (Barea y Monzón, 2002). En cualquier caso, de acuerdo con Toscano (2000), se trata de iniciativas muy diversas que, en esencia, pretenden cubrir aquellas lagunas que ni el mercado en su función asignativa, ni la intervención pública correctora de las desigualdades pueden colmar. Ya que tal pretensión se identifica, en primera instancia, con una finalidad de servicio a los miembros componentes o a una colectividad dada - con el consiguiente fomento del bienestar social -, el verdadero germen de la Economía Social radica en la solidaridad.

Con todo, el papel de la Economía Social no se limita a su contribución genérica a una sociedad más plural, participativa, democrática, solidaria y justa, en definitiva; de hecho, el entramado institucional que la integra cuenta con una reconocida capacidad para desempeñar eficazmente múltiples funciones de índole económica, entre las que destacan las siguientes (Chaves y Monzón, 2003; Gómez y Román, 2005):

1. La distribución más igualitaria de la renta y la riqueza, a través de mecanismos como la preferencia otorgada a personas, servicios y factor trabajo respecto al factor capital en el reparto de los beneficios de las cooperativas, o el voluntariado y las donaciones privadas en el ámbito de las organizaciones sin ánimo de lucro.

2. Corrección de desequilibrios en el mercado laboral, tanto en épocas de recesión como de auge económico. La lucha contra la inestabilidad en el empleo, el paro y la exclusión laboral, o la generación de nuevos puestos de trabajo a menudo asociados a los llamados nuevos yacimientos de empleo, así lo confirman.

3. Oferta de servicios de bienestar social en campos en continua expansión: servicios a la tercera edad, infancia y minusválidos, servicios educativos, sanitarios y culturales, ayuda a refugiados y a marginados.

4. Estabilidad económica. El carácter participativo de la Economía Social permite afrontar las crisis con fórmulas flexibles distintas de las tradicionales 
(ajustes de plantilla, expedientes de regulación, cierres de empresas,...), como son la reestructuración de las remuneraciones de los socios o la reactivación de empresas en dificultades a través de su adquisición en propiedad por los propios trabajadores.

5. Desarrollo sostenible. Los valores inherentes a la Economía Social (prácticas democráticas y solidarias, tejido asociativo, formación, voluntariado, cooperación al desarrollo,...) configuran un sustrato favorable al cambio cultural requerido por un estilo de vida más respetuoso con el medio ambiente y la biodiversidad.

6. Autonomía territorial. Al promover la democracia y la participación ciudadana, las entidades de la Economía Social confieren un gran protagonismo a la sociedad civil del territorio en que se asientan a la hora de determinar el modelo de desarrollo de la zona y de controlar la evolución del proceso de crecimiento y cambio estructural.

7. Desarrollo local/rural. La capacidad de la Economía Social para estimular iniciativas de desarrollo endógeno donde el sector privado lucrativo y las autoridades públicas no han logrado hacerlo satisfactoriamente tiene su raíz en fuertes elementos de convergencia entre las funciones anteriores y los rasgos del modelo de desarrollo desde abajo (Montero, 1997; Toscano, 2000; Bel y Cabaleiro, 2002; Coque, 2003; Mozas y Bernal, 2006):

- El carácter del desarrollo local/rural como estrategia integral supone que en su diseño concurren los diferentes ámbitos que determinan el pulso vital del territorio: económico, social, institucional, cultural, histórico, medioambiental, etc., a la vez que el esfuerzo permanente de todos los agentes implicados, incluida la Economía Social, como parte activa del sector empresarial y de las fuerzas vivas locales.

- El desarrollo local/rural es un modelo descentralizado y participativo. Este espíritu cooperativo encuentra un caldo de cultivo propicio en las entidades de la Economía Social, caracterizadas por la democratización en la toma de decisiones.

- El desarrollo local/rural es un proceso reactivador de la economía y dinamizador de la sociedad local, siendo esenciales en este contexto la flexibilidad, el dinamismo y la cultura de la pequeña y mediana empresa, como principal ingrediente del tejido productivo de la mayoría de las iniciativas de desarrollo. La Economía Social ha venido jugando un importante papel en áreas afectadas por la lógica de la desinversión y la reconversión industrial, a menudo mediante la creación de PYMES (cooperativas, sociedades laborales) a instancia de los propios empleados.

- El desarrollo local/rural se fundamenta en la movilización de los recursos de la zona, hecho preceptivo en las experiencias de desarrollo endógeno. 
Las entidades de la Economía Social no son intensivas en capital, debiendo compensar la escasez de medios mediante el empleo adecuado de los recursos del entorno rural (naturales, humanos, técnicos,...) que configuran el potencial endógeno.

- El desarrollo local/rural se halla íntimamente ligado a la vocación emprendedora. Si algo caracteriza el surgimiento de estas iniciativas es la existencia de empresarios y/o el empeño de los trabajadores de llegar a serlo. Ese espíritu es consustancial a la Economía Social, dado el recurso al autoempleo. Y en este contexto, la mujer rural desempeña un papel protagonista, no únicamente como fijadora de la población, sino también como emprendedora rural (Comisión Europea, 2000, Rico y Gómez, 2009a, 2009b).

- El desarrollo local/rural se fundamenta en el capital humano del área: en los trabajadores y en su cualificación, crucial para adecuarse a los requerimientos de las empresas locales. El principio de educación, formación e información es esencial para la competitividad de las empresas de Economía Social, que suelen destinar parte de sus propios fondos a la formación continua de sus socios y trabajadores.

- El desarrollo local/rural persigue la fijación de la población en el territorio, mediante la oferta de puestos de trabajo y calidad de vida en la zona; una meta particularmente importante dentro del medio rural. Aunque las entidades de la Economía Social no se guían por el ánimo de lucro, su presencia implica la creación de riqueza, a menudo orientada a suplir carencias sociales, y también de empleos estables y de calidad (Gómez et al., 2010), anteponiéndose frecuentemente éstos a la propia actividad empresarial.

- El desarrollo local/rural y la función de la Economía Social presentan un enfoque de largo plazo. El primero pretende crear las condiciones para un desarrollo sostenido del territorio, mediante una estrategia de largo alcance. La acción de la Economía Social propende hacia la obtención de resultados duraderos, en forma de beneficios sociales, empleo y bienestar social, y no tanto hacia el logro de efímeros beneficios a corto plazo.

- El desarrollo local/rural promueve la especialización productiva en actividades en las que el área goza de ventaja competitiva, pero a la vez fomenta sectores emergentes como factor de diversificación. Muchos de estos nuevos yacimientos de empleo tienen marcado carácter local, al estar relacionados con los servicios a la comunidad, la provisión de bienes preferentes o el cuidado del medio ambiente. Tales rasgos entroncan con valores como la ausencia de ánimo de lucro, la participación democrática o el objetivo de bienestar social propios de la Economía Social, lo que la 
sitúa en una posición favorable al desarrollo de nuevos nichos de mercado.

- El desarrollo local en áreas rurales está abierto a la iniciativa pública. Aunque en el pasado las autoridades no han sido cruciales en el nacimiento de experiencias de desarrollo endógeno, hoy pueden fomentar la consolidación de las existentes, así como la aparición de otras nuevas, mediante una planificación estratégica atenta a las especificidades de cada zona. Dicho complemento no es ajeno a la Economía Social, mediante normas, estructuras de acompañamiento y políticas (como el impulso del partenariado entre autoridades locales y organizaciones de la Economía Social) orientadas a la creación de entidades y a la mejora de su financiación.

- El desarrollo local/rural y la Economía Social se identifican con el desarrollo sostenible. La supervivencia de una economía local depende de la permanencia de la actividad productiva, máxime en zonas rurales. Ello implica la necesidad de considerar su impacto ambiental, así como la integración de las estrategias de desarrollo y de conservación. El principio de interés por la comunidad inherente a la Economía Social o su inclinación al sostenimiento de actividades en trance de desaparición (artesanía, industria tradicional) la hacen particularmente compatible con la idea de sostenibilidad.

- Las experiencias de desarrollo local/rural presentan una marcada identidad territorial. Las entidades de Economía Social, con o sin ánimo de lucro, se identifican estrechamente con el territorio en que operan. Se suelen constituir allí donde surge una iniciativa o la fuerte convicción personal de poder salir adelante de un conjunto de emprendedores. Buscando mejorar su calidad de vida, tratarán de aprovechar los recursos a su alcance, vinculando a menudo su actividad a las necesidades locales y tendiendo a reinvertir beneficios en la zona, lo que conjura el riesgo de traslado o cierre selectivo, típico de los procesos de deslocalización.

Por consiguiente, desarrollo local y Economía Social constituyen factores trascendentales para el entorno rural. El afán de reactivación económica, el aprovechamiento de los recursos del área, la vinculación de los emprendedores al territorio, la fijación de la población, son elementos de confluencia entre lo "local" y lo "social" con efectos "balsámicos" sobre el mundo rural, considerando sus problemas y las oportunidades de inversión inherentes al apoyo público en los últimos años, con vistas a su diversificación productiva. En este escenario resulta crucial el papel de las empresas y el de figuras como las Asociaciones de agentes de empleo y desarrollo local y los Grupos de Acción Local (GAL), forma representativa de partenariado a escala microterritorial. 


\section{LA ECONOMÍA SOCIAL Y EL DESARROLLO TERRITORIAL EN CASTILLA Y LEÓN}

Una vez identificadas las posibles sinergias entre desarrollo local/rural y Economía Social, cabe preguntarse cómo se plasman en la práctica en un ámbito territorial concreto, como es el de la Comunidad Autónoma de Castilla y León. No obstante, teniendo presente que los procesos de desarrollo local/rural se enmarcan en contextos territoriales más amplios, resulta conveniente realizar previamente un análisis a nivel nacional, identificando algunos aspectos generales.

\subsection{Economía Social y Desarrollo Local/Rural en España: aspectos generales}

El análisis de la literatura sobre Economía Social y desarrollo local/rural en España permite realizar las siguientes consideraciones de orden general:

- Los procesos de desarrollo local en áreas rurales cobran especial importancia como respuesta, a menudo autónoma, a la crisis industrial de los 70. Las experiencias más representativas, muchas con una dilatada tradición, giran en torno al dinamismo industrial, cristalizando en la configuración de Sistemas Productivos Locales (SPL).

- Los SPL españoles, por lo común con base en la PYME, suelen localizarse en ciudades medias o cabeceras de comarca de áreas rurales, a escala municipal, y, preferentemente, en las Comunidades Autónomas del Arco Mediterráneo y el Valle del Ebro, a escala regional 6, en claro contraste con la realidad de regiones del interior como Castilla y León.

- España cuenta en la actualidad con uno de los más altos porcentajes de empleo a nivel europeo en Economía Social, siendo las cooperativas y las sociedades laborales las entidades más representativas. Dichas entidades vienen mostrando una elevada capacidad para generar empleo y una mayor resistencia ante su destrucción en fases de crisis (si bien la actual ha truncado su ascenso), merced a mecanismos flexibles de difícil aceptación en otras firmas, como el ajuste de la jornada laboral o de los salarios (Figura 1).

- Tradicionalmente se ha tratado de entidades localizadas en zonas rurales y áreas urbanas en declive o deprimidas, impulsando sus inversiones

\footnotetext{
${ }^{6}$ Muchas de esas experiencias presentan una marcada base cooperativa, merced a la configuración de grandes grupos de Economía Social, como es el caso de Mondragón en Guipúzcoa o de Guissona en Lérida. En Castilla y León la industrialización de raíz local se limita a un número reducido de experiencias- no más de una veintena -, entre las que destacan Aranda de Duero, Tierra de Pinares, Ponferrada, Guijuelo, Cantimpalos, Íscar, la Ribera del Duero y Medina del Campo (Juste, 2001; Juste et al., 2007).
} 
procesos de revitalización económica. En los últimos años, no obstante, se viene asistiendo al surgimiento de entidades sociales, PYMES en su inmensa mayoría, en múltiples actividades intensivas en factor trabajo, como es el caso de los servicios de ayuda a personas dependientes, enseñanza, servicios de limpieza, agricultura ecológica, turismo rural o los ámbitos de inserción laboral y de lucha contra la exclusión.

- Esa expansión no ha sido homogénea desde la óptica territorial, como demuestran las cifras de trabajadores y empresas en las diferentes Comunidades Autónomas. Así, la Figura 2 refleja el mayor peso de Andalucía, País Vasco, Comunidad Valenciana y Cataluña, con porcentajes de participación en la Economía Social por encima del 10\%, en contraste con Castilla y León, cuyo menor dinamismo en cuanto a la creación de empleo en cooperativas y sociedades laborales se traduce en una contribución muy inferior (del 4,04\%) ${ }^{7}$.

Figura 1

Evolución del número total de trabajadores en cooperativas y sociedades laborales en España (miles de trabajadores)

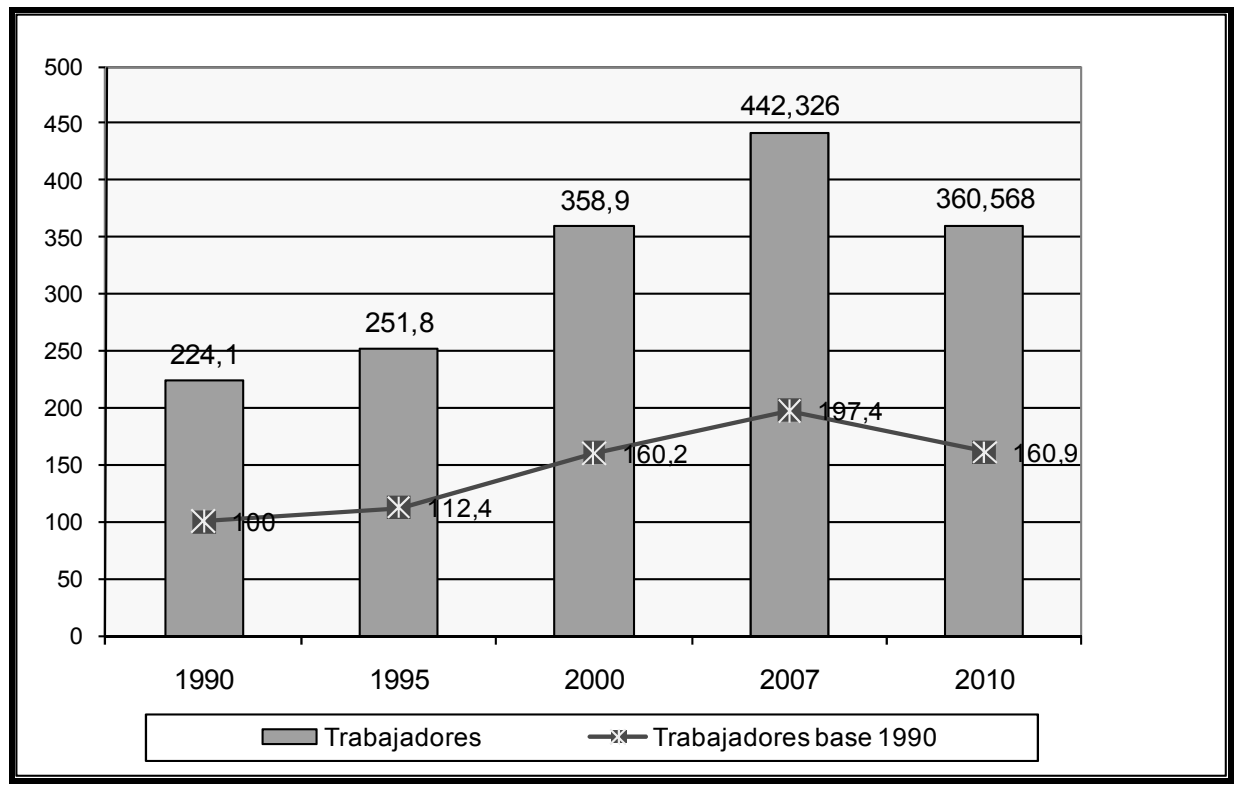

Fuente: Elaboración propia a partir de los Datos de la Dirección General de la Economía Social, del Trabajo Autónomo y del Fondo Social Europeo. Ministerio de Trabajo y Asuntos Sociales.

7 Algo que no deja de llamar la atención, teniendo en cuenta su tamaño geográfico y demográfico, especialmente si se compara con regiones menos extensas y pobladas como Murcia, Navarra o Canarias. 
Figura 2

Distribución regional del número de trabajadores en cooperativas y sociedades laborales a $30-09-2010(\%)$

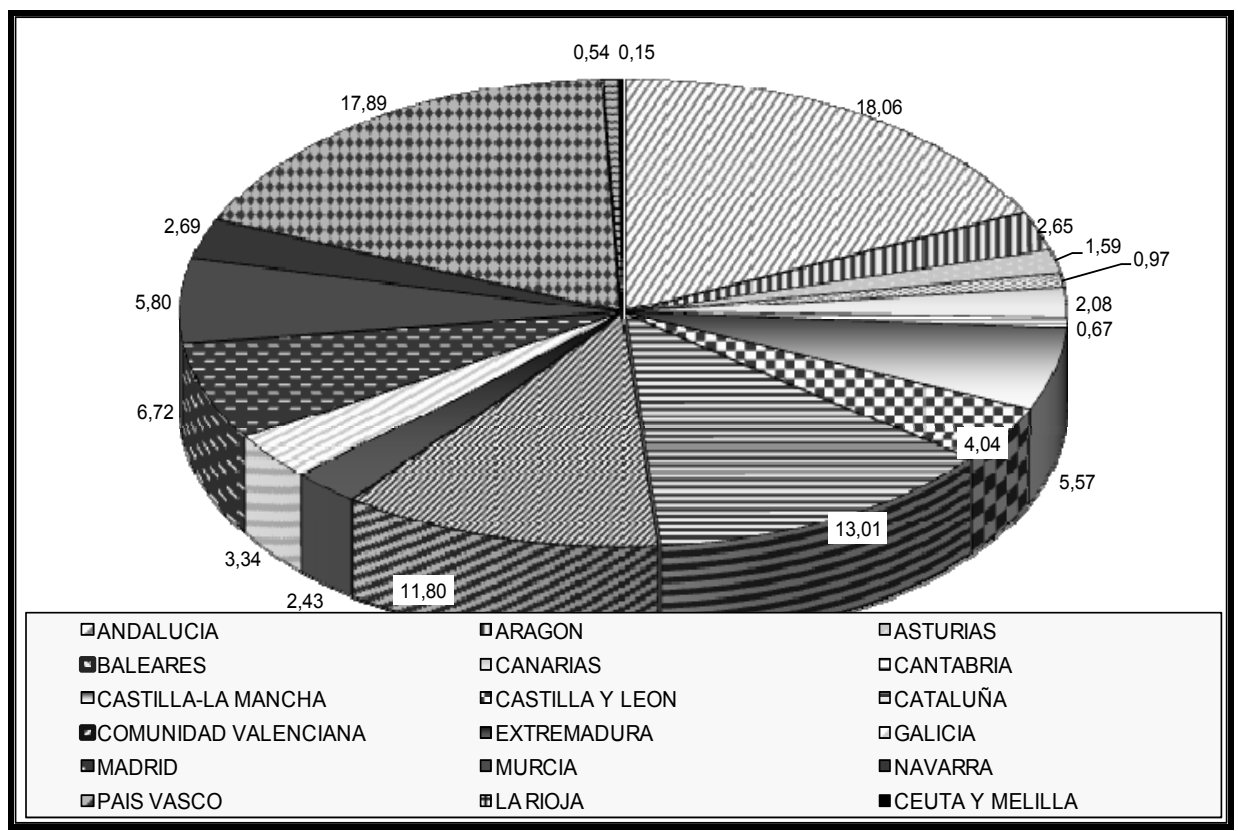

Fuente: Elaboración propia a partir de los Datos de la Dirección General de la Economía Social, del Trabajo Autónomo y del Fondo Social Europeo. Ministerio de Trabajo y Asuntos Sociales.

- Dicho comportamiento es resultado de una alta y heterogénea natalidad empresarial, que arroja una desigual distribución territorial de las unidades productivas. De hecho, en el panorama nacional de la Economía Social, tan sólo tres regiones, Andalucía, Cataluña y la Comunidad Valenciana, aglutinan el $48,3 \%$ del número total de entidades. El porcentaje correspondiente a Castilla y León resulta muy modesto $(5,68 \%)$, registrando la región la menor dimensión media por entidad $(6,8$ trabajadores, frente a los 9,6 de España).

- Este menor peso específico de Castilla y León se halla en sintonía con el menor protagonismo de la Economía Social en su tejido productivo, como lo muestra el reducido porcentaje que sus entidades suponen sobre la población ocupada total de la región $(1,4 \%)$. Dicha cifra, sensiblemente inferior a la media nacional $(2,1 \%)$, queda, como se recoge en el Cuadro 1, muy por debajo de las registradas por regiones como el País Vasco (7\%), Murcia (4,1\%), Navarra (3,5\%), Comunidad Valenciana $(2,9 \%)$ o Andalucía $(2,6 \%)$. 


\section{Cuadro 1}

Población ocupada en Economía Social (cooperativas y sociedades laborales) respecto a población ocupada total, por sectores productivos a 31-12-2009 (\%)

\begin{tabular}{|l|rrcc|c|}
\hline \multicolumn{1}{|c|}{ Regiones } & Agricultura & Industria & Construcción & Servicios & Total \\
\hline Andalucia & 4,18 & 5,14 & 2,33 & 2,13 & $\mathbf{2 , 5 9}$ \\
Aragón & 1,49 & 2,36 & 1,32 & 1,39 & $\mathbf{1 , 5 6}$ \\
Asturias & 1,40 & 1,43 & 1,24 & 1,64 & $\mathbf{1 , 5 6}$ \\
Baleares & 0,63 & 0,55 & 0,39 & 0,87 & $\mathbf{0 , 7 8}$ \\
Canarias & 1,51 & 2,04 & 0,73 & 0,96 & $\mathbf{1 , 0 1}$ \\
Cantabria & 0,19 & 1,95 & 0,92 & 0,81 & $\mathbf{0 , 9 9}$ \\
Castilla-La Mancha & 3,13 & 4,36 & 2,55 & 1,75 & $\mathbf{2 , 3 7}$ \\
Castilla y León & 2,52 & 2,20 & 1,24 & 1,10 & $\mathbf{1 , 4 0}$ \\
Cataluña & 1,39 & 1,56 & 1,26 & 1,53 & $\mathbf{1 , 5 1}$ \\
Comunidad Valenciana & 19,71 & 2,00 & 1,31 & 2,59 & $\mathbf{2 , 8 9}$ \\
Extremadura & 1,64 & 5,06 & 2,56 & 1,65 & $\mathbf{2 , 1 0}$ \\
Galicia & 0,92 & 1,93 & 1,14 & 0,85 & $\mathbf{1 , 0 6}$ \\
Madrid & 0,52 & 0,77 & 0,79 & 0,89 & $\mathbf{0 , 8 6}$ \\
Murcia & 9,04 & 3,71 & 4,21 & 3,42 & $\mathbf{4 , 1 3}$ \\
Navarra & 3,64 & 4,56 & 5,60 & 2,61 & $\mathbf{3 , 4 6}$ \\
País Vasco & 1,35 & 12,29 & 3,56 & 5,74 & $\mathbf{7 , 0 1}$ \\
La Rioja & 0,36 & 2,45 & 0,43 & 1,03 & $\mathbf{1 , 2 6}$ \\
Ceuta y Melilla & 0,00 & 2,06 & 0,86 & 1,12 & $\mathbf{1 , 1 3}$ \\
\hline ESPAÑA & $\mathbf{4 , 3 8}$ & $\mathbf{3 , 1 7}$ & $\mathbf{1 , 6 3}$ & $\mathbf{1 , 7 8}$ & $\mathbf{2 , 0 7}$ \\
\hline
\end{tabular}

Fuente: Elaboración propia a partir de los Datos de la Dirección General de la Economía Social, del Trabajo Autónomo y del Fondo Social Europeo. Ministerio de Trabajo y Asuntos Sociales.

Como se observa, a escala intrasectorial, el sector con mayor grado de penetración de la Economía Social es la agricultura - especialmente en la Comunidad Valenciana -, al suponer ésta el 4,4\% del empleo agrario nacional. Le sigue la industria, donde sociedades laborales y cooperativas generan el $3,2 \%$ del empleo (con penetración máxima en el País Vasco). Los menores porcentajes corresponden a la construcción y al terciario, con el 1,6\% y el 1,8\%, respectivamente (destacando Navarra y País Vasco). La incidencia de la Economía Social en Castilla y León es inferior a la media nacional en todos los sectores ${ }^{8}$, resultando un menor grado de especialización general de la región en este ámbito respecto a España $(0,67)$, en contraste con el País Vasco, Navarra, Murcia, la Comunidad Valenciana o Andalucía (Figura 3).

\footnotetext{
${ }^{8}$ Por sectores productivos, destaca, a escala nacional, la creación de empleo en el secundario (el 23,2\% del empleo total de la Economía Social) y, sobre todo, en el terciario (el 61,7\%). La positiva evolución registrada en los últimos años en todos los sectores se truncó en 2008 por la actual crisis, destacando el impacto en la construcción (con una caída en 2010 del $47 \%$ respecto a 2007 , pasando del $12,6 \%$ al $8,1 \%$ del empleo generado por cooperativas y sociedades laborales a escala nacional).
} 
Figura 3

Grado de especialización en el empleo en Economía Social (cooperativas y sociedades laborales) de las regiones españolas por sectores productivos a 31-12-2009 (\%)

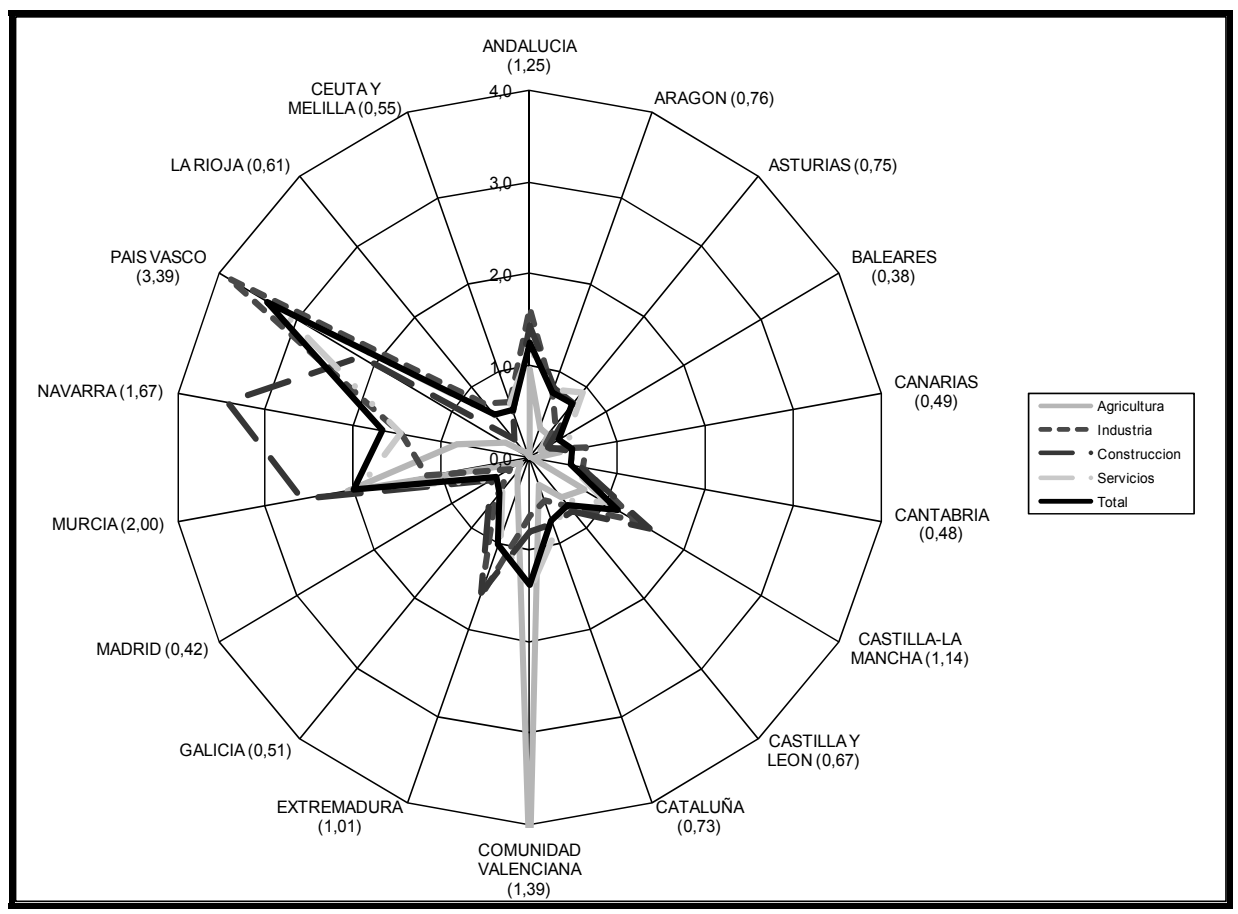

Fuente: Elaboración propia a partir de los Datos de la Dirección General de la Economía Social, del Trabajo Autónomo y del Fondo Social Europeo. Ministerio de Trabajo y Asuntos Sociales.

\subsection{Economía Social y desarrollo Local/Rural en Castilla y León: principales sinergias}

El análisis anterior pone de manifiesto que, en términos generales, la Economía Social en Castilla y León, en su segmento mercado, no alcanza la dimensión ni el grado de penetración en el tejido productivo que presenta en otras partes de España. No obstante, cabe albergar expectativas respecto a un amplio potencial de expansión futura de este sector en la región.

Aun admitiendo, en consecuencia, que su impacto territorial va a ser más limitado que en otras Comunidades Autónomas, la aproximación a la realidad de la Economía Social como vehículo de desarrollo local/rural en Castilla y León requiere un análisis más profundo; un examen, a nuestro juicio, que permita verificar de algún modo la plasmación de los puntos de convergencia identificados previamente (o, al menos, de buena parte de ellos). 
Para efectuar dicha labor partimos de los resultados obtenidos en un estudio sobre la situación actual y los rasgos de la Economía Social en Castilla y León, realizado con base en una encuesta lanzada a un universo de 2.600 empresas ${ }^{9}$ : Cooperativas (el $41,5 \%$ del total), Sociedades Laborales $(52,9 \%)$ y Centros Especiales de Empleo (C.E.E.) (5,6\%).

Una población empresarial que, como recoge el Cuadro 2, se ubica preferentemente en las provincias de Valladolid y León - ambas con el 19,1\% del total regional -, cuyo peso es más notorio en los sectores no agrarios de la región y en el número total de sociedades laborales y Centros Especiales de Empleo (C.E.E.). Les siguen Salamanca y Burgos (16,8\% y 14,6\% del total, respectivamente), con la más amplia presencia de cooperativas, destacando en la agricultura e industria regionales; finalmente, con la menor participación, figuran, en general, las cinco provincias menos pobladas.

\section{Cuadro 2}

Distribución provincial de las empresas de Economía Social por sectores

\begin{tabular}{|c|c|c|c|c|c|c|c|c|c|c|}
\hline \multirow{2}{*}{ Provincias } & \multicolumn{5}{|c|}{$\%$ s/total regional } & \multicolumn{5}{|c|}{$\%$ s/total provincial } \\
\hline & Agric. & Ind. & Const. & Serv. & Total & Agri. & Ind. & Const. & Serv. & Total \\
\hline AVILA & 5,68 & 4,70 & 5,37 & 5,03 & 5,12 & 22,56 & 20,30 & 9,77 & 47,37 & 100,00 \\
\hline BURGOS & 17,99 & 15,13 & 12,81 & 13,33 & 14,63 & 25,00 & 22,89 & 8,16 & 43,95 & 100,00 \\
\hline LEÓN & 10,23 & 15,65 & 27,27 & 22,83 & 19,09 & 10,89 & 18,15 & 13,31 & 57,66 & 100,00 \\
\hline PALENCIA & 10,23 & 8,52 & 6,20 & 6,30 & 7,58 & 27,41 & 24,87 & 7,61 & 40,10 & 100,00 \\
\hline SALAMANCA & 24,05 & 16,52 & 15,70 & 14,13 & 16,82 & 29,06 & 21,74 & 8,70 & 40,50 & 100,00 \\
\hline SEGOVIA & 6,06 & 4,52 & 2,07 & 3,91 & 4,31 & 28,57 & 23,21 & 4,46 & 43,75 & 100,00 \\
\hline SORIA & 3,41 & 8,52 & 5,79 & 3,75 & 4,93 & 14,06 & 38,28 & 10,94 & 36,72 & 100,00 \\
\hline VALLADOLID & 11,55 & 18,26 & 18,18 & 22,83 & 19,09 & 12,30 & 21,17 & 8,87 & 57,66 & 100,00 \\
\hline ZAMORA & 10,80 & 8,17 & 6,61 & 7,90 & 8,43 & 26,03 & 21,46 & 7,31 & 45,21 & 100,00 \\
\hline $\begin{array}{l}\text { CASTILLA Y } \\
\text { LEÓN }\end{array}$ & 100,00 & 100,00 & 100,00 & 100,00 & 100,00 & 20,32 & 22,13 & 9,31 & 48,23 & 100,00 \\
\hline
\end{tabular}

Fuente: Elaboración propia a partir de los datos de la encuesta.

A escala intraprovincial se detecta un importante grado de terciarización de la Economía Social, al situarse en el sector servicios el 48,2\% de las empresas,

\footnotetext{
${ }^{9}$ El proyecto, financiado por la Junta de Castilla y León, lleva por título "La Economía Social en Castilla y León. Estudio del sector empresarial". La encuesta fue efectuada de manera telefónica entre el 19 de junio y el 6 de julio de 2006. Respondieron un total de 1.191 empresas, con una tasa de respuesta del $45 \%$ y un margen de error del $\pm 2,25 \%$ para datos globales en condiciones normales de muestreo $(\mathrm{p}=\mathrm{q}=0,5,2 \sigma)$, con un nivel de confianza del $95,5 \%$. Se plantearon 4 tipos de cuestionarios: uno para Centros Especiales de Empleo, otro para Cooperativas de Vivienda, otro para Cooperativas de Crédito y un cuarto para las demás clases de Cooperativas y las Sociedades Laborales.
} 
cifra que se eleva al $56 \%$ si se tiene presente que hasta un 39\% de las que cabría calificar como agrarias tienen por actividad dominante la comercialización de productos agrarios. Dicha terciarización es especialmente intensa en Valladolid y León (57,7\% de la Economía Social provincial en ambos casos), registrando el valor mínimo en Soria $(36,7 \%)$, donde destaca el sector manufacturero, con una cifra - 38,3\% - muy superior a la media regional (22,1\%). El sector agrario sobresale en las provincias de Salamanca, Segovia, Palencia y Zamora, y la construcción registra su más alto porcentaje en la provincia de León (13,3\%).

Los datos de la muestra objeto de análisis revelan una composición societaria muy diversa (Figura 4). Mientras el $81 \%$ de las sociedades laborales cuenta con un número de socios inferior a 5 , dicha cifra se reduce al $33,1 \%$ para las cooperativas, pues algunas de sus categorías (agrarias, de vivienda, de crédito) cuentan con un elevado número de socios que conduce a un promedio de 202,6 socios por cooperativa (frente a los 4,7 socios de las sociedades laborales). No obstante, en las cooperativas, los socios son, por lo común, no trabajadores y/o usuarios (97,3\%), en tanto que en las sociedades laborales el porcentaje de socios trabajadores llega a alcanzar el 62,3\%, siendo socios capitalistas el resto.

Figura 4

Distribución porcentual de cooperativas y sociedades laborales por $n^{\circ}$ de socios

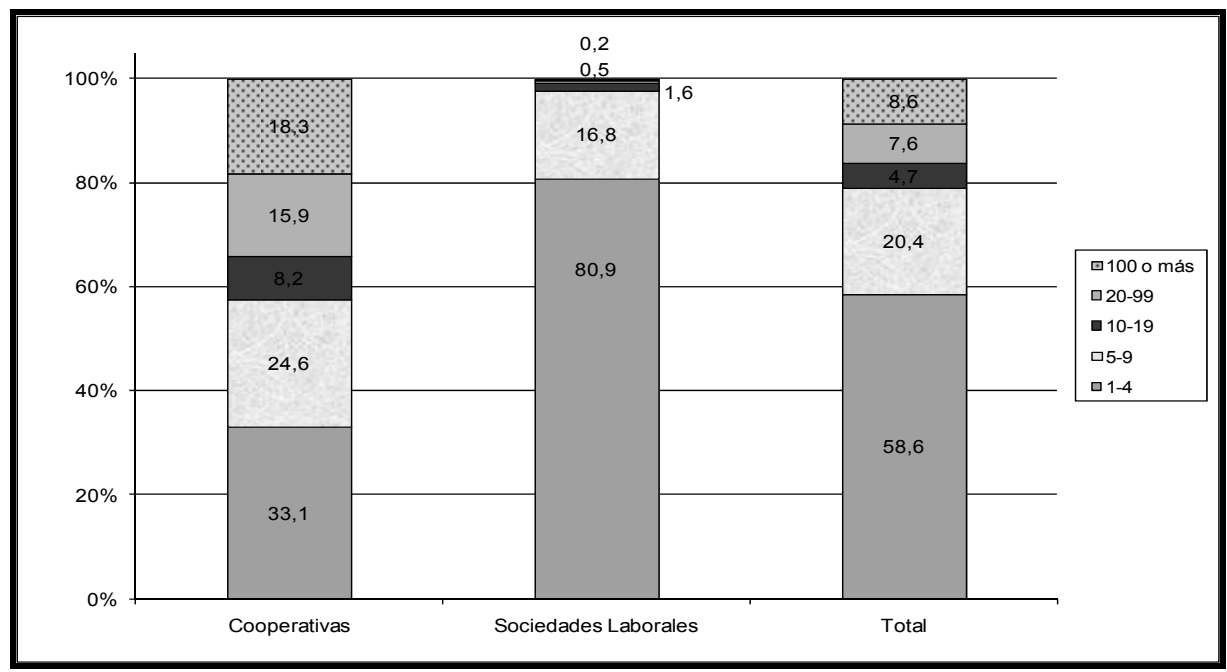

Fuente: Elaboración propia a partir de los datos de la encuesta.

En todo caso, como refleja el Cuadro 3, el tamaño medio de estas entidades es muy reducido: 9,3 puestos de trabajo (inflado por la mayor dimensión de los C.E.E.), y con un claro predominio de las empresas que dan ocupación a menos 
de 4 personas (el $58,6 \%$ del total), sobre todo en el caso de las sociedades laborales. Se trata, pues, de PYMES - o, mejor, de microempresas -, rasgo acorde con el panorama productivo dominante en los procesos de desarrollo local/rural, cuyo impacto económico resulta más notable en las cooperativas (que generan el 52,5\% del empleo y el $69 \%$ de la producción en Economía Social); en consonancia con este último dato, dicha categoría registra los mayores niveles de facturación por empresa y de productividad aparente del trabajo (2,1 millones de $€$ y $200.000 €$, respectivamente).

\section{Cuadro 3}

Contribución al empleo y la producción de la Economía Social (\%)

\begin{tabular}{|l|rrr|r|}
\hline \multicolumn{1}{|c|}{ Población ocupada } & Cooperativas & $\begin{array}{c}\text { Sociedades } \\
\text { Laborales }\end{array}$ & $\begin{array}{c}\text { Centros } \\
\text { Esp. Empleo }\end{array}$ & \multicolumn{1}{c|}{ Total } \\
\hline 2 o menos & 34,6 & 34,3 & 17,3 & $\mathbf{3 2 , 9}$ \\
$3-4$ & 22,6 & 31,5 & 14,4 & $\mathbf{2 5 , 7}$ \\
$5-9$ & 21,7 & 23,0 & 28,8 & $\mathbf{2 2 , 9}$ \\
$10-19$ & 12,0 & 8,5 & 14,4 & $\mathbf{1 0 , 7}$ \\
$20-99$ & 7,4 & 2,8 & 23,1 & $\mathbf{6 , 8}$ \\
100 o más & 1,6 & 0,0 & 1,9 & $\mathbf{1 , 0}$ \\
\hline Total & $\mathbf{1 0 0 , 0}$ & $\mathbf{1 0 0 , 0}$ & $\mathbf{1 0 0 , 0}$ & $\mathbf{1 0 0 , 0}$ \\
\hline Tamaño medio & 10,5 & 5,2 & 22,1 & $\mathbf{9 , 3}$ \\
Contribución a empleo & 52,5 & 32,7 & 14,8 & $\mathbf{1 0 0 , 0}$ \\
\hline Contribución a producción & 69,0 & 24,3 & 6,7 & $\mathbf{1 0 0 , 0}$ \\
Facturación/empresa $(€)$ & 2116450,0 & 503988,4 & 1305729,2 & $\mathbf{1 3 6 4 8 0 5 , \mathbf { 1 }}$ \\
Productividad media tbjo. & 201566,7 & 96920,8 & 59082,8 & $\mathbf{1 4 6 7 5 3 , 2}$ \\
\hline
\end{tabular}

Fuente: Elaboración propia a partir de los datos de la encuesta.

Considerando el empleo asalariado, el Cuadro 4 corrobora lo anterior: así, casi un tercio de las cooperativas y sociedades laborales no emplean a ningún trabajador por cuenta ajena, claro indicio del recurso al autoempleo, presentando casi el $75 \%$ menos de 4 trabajadores (cifra que roza las cuatro quintas partes en las sociedades laborales). 


\section{Cuadro 4}

Estructura laboral por número de asalariados y tipos de contrato (\%)

\begin{tabular}{|l|rr|r|}
\hline \multicolumn{1}{|c|}{ Total empleados } & Cooperativas & $\begin{array}{c}\text { Sociedades } \\
\text { Laborales }\end{array}$ & \multicolumn{1}{c|}{ Total } \\
\hline 0 & 31,7 & 31,3 & $\mathbf{3 1 , 5}$ \\
$1-2$ & 20,4 & 27,6 & $\mathbf{2 3 , 8}$ \\
$3-4$ & 16,2 & 20,1 & $\mathbf{1 8 , 0}$ \\
\hline $5-9$ & 15,7 & 12,9 & $\mathbf{1 4 , 4}$ \\
$10-19$ & 7,7 & 5,5 & $\mathbf{6 , 7}$ \\
$20-99$ & 6,5 & 2,6 & $\mathbf{4 , 7}$ \\
100 o más & 1,7 & 0,0 & $\mathbf{0 , 9}$ \\
\hline Total & $\mathbf{1 0 0 , 0}$ & $\mathbf{1 0 0 , 0}$ & $\mathbf{1 0 0 , 0}$ \\
\hline Contratados indefinidos & 75,8 & 53,8 & $\mathbf{7 0 , 5}$ \\
Contratados temporales & 24,2 & 46,2 & $\mathbf{2 9 , 5}$ \\
\hline
\end{tabular}

Fuente: Elaboración propia a partir de los datos de la encuesta.

Respecto a la modalidad de contratación, algo más del 70\% son contratos indefinidos, especialmente en las cooperativas, en cuyo seno la contratación temporal representa algo menos del $25 \%$. Al autoempleo y relativa estabilidad laboral - propios del fenómeno del desarrollo local/rural - les acompaña un apreciable grado de democratización en el ámbito decisorio, jugando la Asamblea General de socios un papel relevante en más del 35\% de los casos en la adopción de decisiones de gestión, laborales y, sobre todo, de carácter estratégico (39,8\%), seguida del Consejo Rector en las cooperativas y del Consejo de Administración en las sociedades laborales (Cuadro 5).

\section{Cuadro 5}

Responsabilidad de los órganos de la empresa en la toma de decisiones

\begin{tabular}{|l|rrr|}
\hline \multicolumn{1}{|c|}{ Órganos de la empresa } & De gestión & Laborales & Estratégicas \\
\hline Director o gerente & 22,1 & 20,2 & 16,8 \\
Presidente o administrador & 13,6 & 13,4 & 12,4 \\
Consejo Rector o Consejo de Administración & 29,0 & 30,5 & 31,0 \\
Asamblea o Junta de Socios & 35,3 & 36,0 & 39,8 \\
\hline Total & $\mathbf{1 0 0 , 0}$ & $\mathbf{1 0 0 , 0}$ & $\mathbf{1 0 0 , 0}$ \\
\hline
\end{tabular}

Fuente: Elaboración propia a partir de los datos de la encuesta.

El nivel de formación dominante entre el personal de estas entidades es el de los estudios primarios (40,9\%), siendo escaso el personal sin estudios $(8,7 \%)$, sobre todo en las sociedades laborales $(1,7 \%)$, donde destacan los estudios 
secundarios (43,8\%). En los Consejos Rectores o de Administración predominan los miembros con estudios primarios o secundarios, así como los directivos de cooperativas y sociedades laborales; no así en el caso de los C.E.E., donde adquieren relevancia los estudios universitarios (al igual que en algunas clases de cooperativas, como son las de enseñanza y las de crédito).

\section{Cuadro 6}

Niveles formativos por tipos de personal y empresas (\%)

\begin{tabular}{|c|c|c|c|c|c|c|}
\hline $\begin{array}{l}\text { Tipo de } \\
\text { empresa }\end{array}$ & $\begin{array}{l}\text { Nivel de } \\
\text { estudios }\end{array}$ & $\begin{array}{c}\text { Total por tipo } \\
\text { de empresa } \\
(\%)\end{array}$ & $\begin{array}{l}\text { Consejo } \\
\text { Rector } \\
\text { o de } \\
\text { Admón. }\end{array}$ & $\begin{array}{l}\text { Personal } \\
\text { de } \\
\text { dirección }\end{array}$ & $\begin{array}{c}\text { Resto } \\
\text { plantilla }\end{array}$ & Total \\
\hline \multirow[t]{4}{*}{ Cooperativas } & Sin estudios & 10,0 & 12,2 & 6,2 & 81,7 & 100,0 \\
\hline & Primarios & 41,4 & 49,4 & 15,3 & 35,3 & 100,0 \\
\hline & Secundarios & 25,1 & 39,4 & 18,5 & 42,1 & 100,0 \\
\hline & Universitarios & 23,5 & 24,6 & 8,3 & 67,1 & 100,0 \\
\hline \multirow{4}{*}{$\begin{array}{c}\text { Sociedades } \\
\text { Laborales }\end{array}$} & Sin estudios & 1,7 & 40,6 & 25,0 & 34,4 & 100,0 \\
\hline & Primarios & 37,3 & 29,7 & 17,2 & 53,1 & 100,0 \\
\hline & Secundarios & 43,8 & 34,9 & 24,0 & 41,1 & 100,0 \\
\hline & Universitarios & 17,3 & 37,4 & 30,8 & 31,7 & 100,0 \\
\hline \multirow{4}{*}{$\begin{array}{c}\text { Centros } \\
\text { Especiales de } \\
\text { Empleo }\end{array}$} & Sin estudios & 12,1 & 1,3 & 0,0 & 98,7 & 100,0 \\
\hline & Primarios & 43,7 & 3,7 & 1,5 & 94,8 & 100,0 \\
\hline & Secundarios & 28,9 & 12,3 & 8,6 & 79,1 & 100,0 \\
\hline & Universitarios & 15,4 & 27,7 & 25,1 & 47,1 & 100,0 \\
\hline \multirow[t]{4}{*}{ TOTAL } & Sin estudios & 8,7 & & & & \\
\hline & Primarios & 40,9 & & & & \\
\hline & Secundarios & 29,0 & & & & \\
\hline & Universitarios & 21,4 & & & & \\
\hline
\end{tabular}

Fuente: Elaboración propia a partir de los datos de la encuesta.

Respecto a la formación no reglada, el personal de más de la mitad de las empresas de Economía Social ha asistido a cursos de formación y/o perfeccionamiento profesional en los últimos dos años. La participación media es del 62\%; de hecho, en casi el 50\% de los casos ha asistido más del $60 \%$ de la plantilla, especialmente en los C.E.E. (Cuadro 7). Todos estos datos traslucen, no obstante, la existencia de importantes necesidades formativas, cara al fomento del capital humano como recurso primordial en los procesos de desarrollo local/rural. 


\section{Cuadro 7}

Porcentaje de la plantilla participante en cursos de formación

\begin{tabular}{|l|rrr|r|}
\hline $\begin{array}{c}\text { Porcentaje de la plantilla } \\
\text { participante en cursos }\end{array}$ & Cooperativas & $\begin{array}{c}\text { Sociedades } \\
\text { Laborales }\end{array}$ & $\begin{array}{c}\text { Centros } \\
\text { Esp. Empleo }\end{array}$ & \multicolumn{1}{c|}{ Total } \\
\hline $0-20$ & 16,9 & 14,7 & 11,3 & $\mathbf{1 5 , 4}$ \\
$21-41$ & 17,2 & 19,3 & 9,7 & $\mathbf{1 7 , 3}$ \\
$41-60$ & 17,6 & 23,2 & 24,2 & $\mathbf{2 0 , 6}$ \\
$61-80$ & 11,0 & 7,3 & 14,5 & $\mathbf{9 , 8}$ \\
\hline $81-100$ & 37,2 & 35,5 & 40,3 & $\mathbf{3 6 , 8}$ \\
\hline Total & $\mathbf{1 0 0 , 0}$ & $\mathbf{1 0 0 , 0}$ & $\mathbf{1 0 0 , 0}$ & $\mathbf{1 0 0 , 0}$ \\
\hline \% medio de participación & 62,1 & 60,3 & 68,7 & $\mathbf{6 2 , 0}$ \\
\hline
\end{tabular}

Fuente: Elaboración propia a partir de los datos de la encuesta.

La antigüedad media de las empresas analizadas es de unos 12,5 años, siendo las cooperativas las más veteranas. La gran mayoría de cooperativas y sociedades laborales surgió por iniciativa de los socios, en situación de paro en casi el $50 \%$ de los casos. Este carácter reactivo frente a la adversidad, consustancial al inicio de todo proceso de desarrollo local/rural, sigue marcando el comportamiento estratégico de más de un tercio de estas entidades (sobre todo cooperativas), que tiene como prioridad la supervivencia de la empresa, afrontando la presión del mercado mediante los recursos disponibles.

Con todo, conviene señalar el comportamiento prospectivo, abierto a innovaciones y nuevos mercados, como elemento distintivo en más del $25 \%$ de los casos (sociedades laborales y C.E.E.). De hecho, en relación con la innovación (Cuadro 8), una notable proporción de empresas $(50,6 \%)$ declara haber innovado recientemente (hasta el $68,3 \%$ en los C.E.E.), con un claro predominio de la innovación de proceso sobre las de producto y organizativas (ambas, de nuevo, con un peso llamativo en los C.E.E.).

Cuadro 8

Actividad empresarial innovadora en los últimos dos años (\%)

\begin{tabular}{|l|rrr|r|}
\hline \multicolumn{1}{|c|}{ Concepto } & Cooperativas & $\begin{array}{c}\text { Sociedades } \\
\text { Laborales }\end{array}$ & $\begin{array}{c}\text { Centros } \\
\text { Esp. Empleo }\end{array}$ & \multicolumn{1}{|c|}{ Total } \\
\hline Alguna forma de innovación & 51,4 & 46,0 & 68,3 & $\mathbf{5 0 , 6}$ \\
Innovación organizativa & 17,6 & 17,8 & 23,1 & $\mathbf{1 9 , 3}$ \\
Innovación de producto & 18,2 & 17,8 & 35,6 & $\mathbf{1 8 , 8}$ \\
Innovación de proceso & 42,8 & 33,4 & 26,9 & $\mathbf{3 9 , 6}$ \\
\hline Actividades de I+D (*) & 14,3 & 16,4 & 52,9 & $\mathbf{1 6 , 0}$ \\
Empresas $\left(^{*}\right)$ que protegen su I+D & 22,7 & 17,7 & 18,4 & $\mathbf{2 0 , 2}$ \\
\hline
\end{tabular}

Fuente: Elaboración propia a partir de los datos de la encuesta. 
Menos frecuente resulta la realización de actividades de $\mathrm{I}+\mathrm{D}$, presentes sobre todo en los C.E.E. (52,9\%), aunque son las cooperativas quienes registran el mayor porcentaje de empresas que, realizando tales actividades, protegen sus resultados $(22,7 \%)$. Esta apertura a la innovación concuerda con una alta penetración de las TICs (Figura 5). Así, las empresas cuentan con buen equipamiento informático (sobre todo C.E.E. y sociedades laborales), fruto de su política inversora, notablemente activa en los últimos dos años en el $55 \%$ de las firmas, y con las instalaciones y equipos de producción como destino primordial en el $87,7 \%$ de los casos, seguido de la mejora en la calidad $(35,1 \%)$. Los recursos propios constituyen la principal fuente de financiación de las inversiones (en el 66,4\% de los casos). Las previsiones acerca de una expansión futura no son muy frecuentes $(34,2 \%$ de los casos), apuntando a la expansión propia como modalidad preferida.

Innovación e inversión reflejan, de cualquier modo, la presencia de una cierta visión de largo plazo - inherente al desarrollo local/rural - que sería más sólida de potenciarse una estrategia competitiva apoyada en la diferenciación del producto y no tanto vía costes.

Figura 5

Política inversora y equipamiento en materia de TICs (\%)

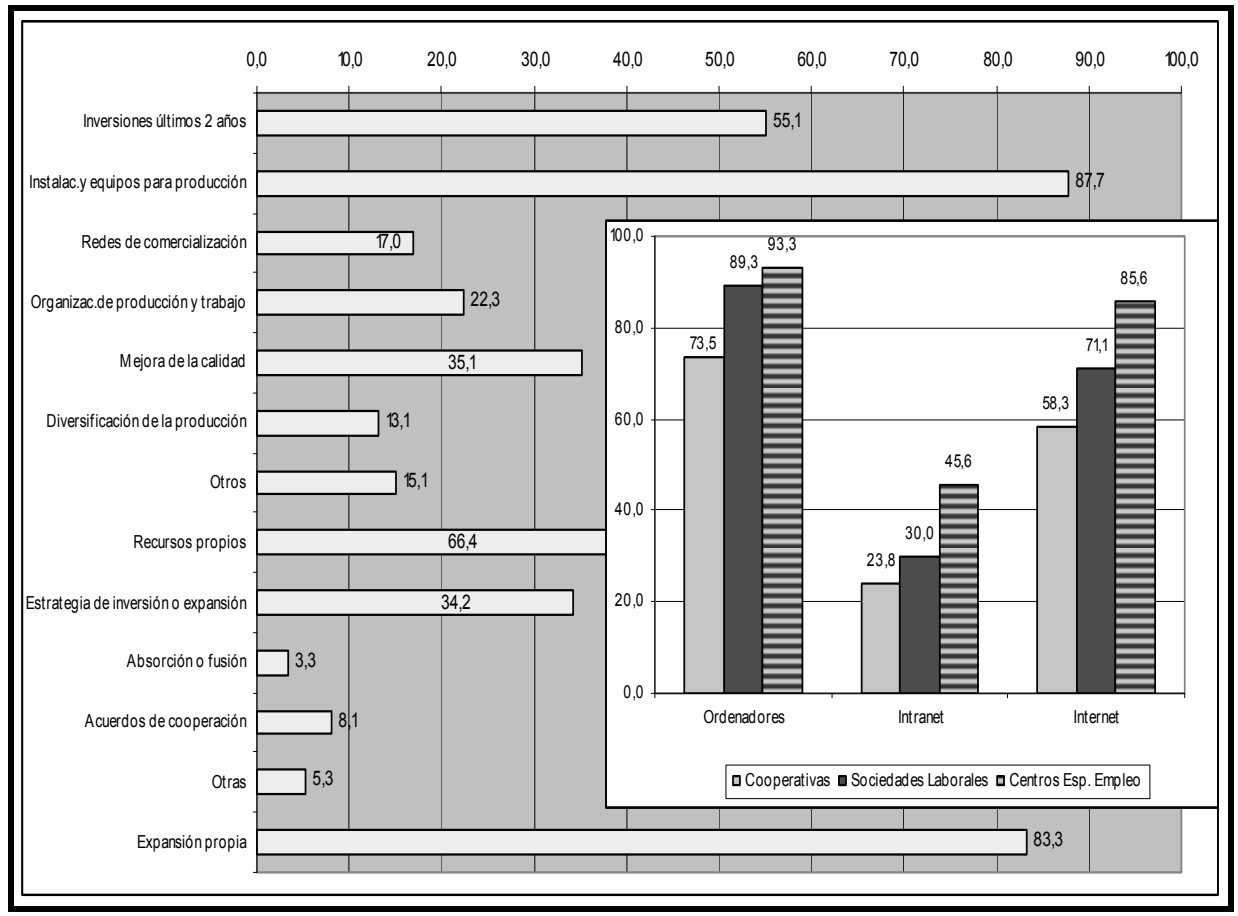

Fuente: Elaboración propia a partir de los datos de la encuesta. 
En esa labor de fomento juega un papel importante, sin duda, el apoyo público. Como refleja el Cuadro 9, un 56\% de las empresas (el 92\% de los C.E.E.) reconoce haber recibido subvenciones en los últimos tres años, procedentes, en su mayoría, de la Administración Regional (hasta el 87,9\% de las firmas que declaran contar con ayudas). El destino principal de las ayudas lo constituyen la inversión en maquinaria $\mathrm{y} / \mathrm{o}$ instalaciones y el fomento del empleo. Esa permeabilidad respecto a la iniciativa pública - palanca de desarrollo local/rural - queda patente si se tiene en cuenta que el apoyo obtenido ha sido determinante en la elección de la forma jurídica de la empresa (sobre todo en las sociedades laborales); en todo caso, las principales demandas de servicios públicos por parte de las empresas giran en torno a la mejora de los sistemas de financiación y de los canales de información.

\section{Cuadro 9}

Ayudas de las Administraciones Públicas (\%)

\begin{tabular}{|l|rrr|r|}
\hline \multicolumn{1}{|c|}{ Concepto } & Cooperativas & $\begin{array}{c}\text { Sociedades } \\
\text { Laborales }\end{array}$ & $\begin{array}{c}\text { Centros } \\
\text { Esp. Empleo }\end{array}$ & Total \\
\hline Reciben ayuda pública & $\mathbf{5 6 , 8}$ & $\mathbf{4 7 , 8}$ & $\mathbf{9 2 , 3}$ & $\mathbf{5 6 , 1}$ \\
\hline De entidades locales & 7,9 & 7,4 & 7,4 & 7,6 \\
De Junta de Castilla y León & 85,5 & 86,8 & 99,0 & 87,9 \\
De alguna entidad nacional & 10,3 & 9,9 & 7,3 & 9,7 \\
De entidades europeas & 30,6 & 7,9 & 8,3 & 19,2 \\
De otras entidades & 4,8 & 4,1 & 5,3 & 4,6 \\
\hline Servicios demandados a las A.A.P.P. & & & & \\
\hline Información & 60,5 & 58,7 & 54,8 & 59,2 \\
Seguimiento de proyecto empresarial & 29,6 & 32,0 & 29,4 & 30,6 \\
Ayuda a obtención de financiación & 63,6 & 68,4 & 68,0 & 66,0 \\
Ayuda integral & 25,3 & 27,5 & 38,8 & 27,4 \\
Otros & 11,5 & 9,7 & 12,7 & 10,8 \\
\hline
\end{tabular}

Fuente: Elaboración propia a partir de los datos de la encuesta.

Un importante número de empresas que operan en el sector terciario tiene como función principal la realización de actividades enmarcadas en los llamados nuevos yacimientos de empleo, generando oportunidades para una mayor diversificación económica en el medio rural. Destacan, en este sentido, los servicios a la vida cotidiana (servicios a domicilio, atención a la infancia, inserción laboral de jóvenes en dificultades) (Cuadro 10) y, en menor medida, los servicios de mejora de la calidad de la vida (como son seguridad y vigilancia, transportes colectivos locales, revalorización de espacios urbanos,...) 
y los servicios orientados al ocio (por ejemplo, el turismo rural, la valorización del patrimonio, el deporte,...).

\section{Cuadro 10}

Nuevos yacimientos de empleo por tipos de empresas (\%)

\begin{tabular}{|l|rrr|r|}
\hline \multicolumn{1}{|c|}{$\begin{array}{c}\text { Ámbitos ocupacionales } \\
\text { (categorías de servicios) }\end{array}$} & Cooperativas & $\begin{array}{c}\text { Sociedades } \\
\text { Laborales }\end{array}$ & $\begin{array}{c}\text { Centros } \\
\text { Esp. Empleo }\end{array}$ & \multicolumn{1}{c|}{ Total } \\
\hline Servicios a la vida cotidiana & 17,4 & 21,0 & 88,9 & $\mathbf{5 7 , 1}$ \\
De mejora de la calidad de vida & 52,2 & 40,3 & 11,1 & $\mathbf{2 6 , 1}$ \\
De ocio & 30,4 & 33,9 & 0,0 & $\mathbf{1 5 , 2}$ \\
Medioambientales & 0,0 & 4,8 & 0,0 & $\mathbf{1 , 6}$ \\
\hline Total & $\mathbf{1 0 0 , 0}$ & $\mathbf{1 0 0 , 0}$ & $\mathbf{1 0 0 , 0}$ & $\mathbf{1 0 0 , 0}$ \\
\hline
\end{tabular}

Fuente: Elaboración propia a partir de los datos de la encuesta.

La presencia de servicios medioambientales es muy inferior; con todo, la valoración que estas entidades realizan de su compromiso con el desarrollo sostenible es notable (Cuadro 11), y muy similar a la referida a su respeto por los valores democráticos y participativos y a su contribución al desarrollo y cohesión social a escala local.

\section{Cuadro 11}

Valoración de las ventajas de la Economía Social (Escala de 1 a 5)

\begin{tabular}{|c|rrrrrr|}
\hline Empresas & $\begin{array}{l}\text { Compromiso } \\
\text { con el medio } \\
\text { ambiente }\end{array}$ & $\begin{array}{c}\text { Responsabilidad } \\
\text { social de la } \\
\text { empresa }\end{array}$ & $\begin{array}{c}\text { Desarrolloy } \\
\text { cohesión } \\
\text { social } \\
\text { anivel local }\end{array}$ & $\begin{array}{c}\text { Valores } \\
\text { solidarios } \\
\text { democráticos } \\
\text { y } \\
\text { participativos }\end{array}$ & $\begin{array}{c}\text { Aplicación del } \\
\text { princ. de } \\
\text { igualdad de } \\
\text { oportunidades }\end{array}$ & $\begin{array}{c}\text { Integración } \\
\text { sociolaboral de } \\
\text { colect. } \\
\text { desfavorecidos }\end{array}$ \\
\hline Cooperativas & 4,1 & 4,1 & 3,9 & 3,9 & 4,0 & 3,6 \\
Soc. laborales & 4,2 & 4,3 & 4,0 & 3,9 & 4,2 & 3,9 \\
C. E. Empleo & 3,9 & 4,4 & 4,0 & 4,0 & 4,4 & 4,7 \\
\hline TOTAL & $\mathbf{4 , 1}$ & $\mathbf{4 , 2}$ & $\mathbf{3 , 9}$ & $\mathbf{3 , 9}$ & $\mathbf{4 , 1}$ & $\mathbf{3 , 8}$ \\
\hline
\end{tabular}

Fuente: Elaboración propia a partir de los datos de la encuesta.

A tales valores no resulta ajena la política de reinversión del excedente: el $72,3 \%$ tiene como destino la autofinanciación de la empresa, frente a un $17 \%$ de retorno a los socios (Cuadro 12). 


\section{Cuadro 12}

Destino del beneficio neto (porcentaje medio por empresa)

\begin{tabular}{|l|rr|r|}
\hline Destino de excedentes (\%) & Cooperativas & $\begin{array}{c}\text { Sociedades } \\
\text { Laborales }\end{array}$ & \multicolumn{1}{|c|}{ Total } \\
\hline Retorno a socios & 24,6 & 9,0 & $\mathbf{1 7 , 2}$ \\
Autofinanciación de la empresa & 63,9 & 81,5 & $\mathbf{7 2 , 3}$ \\
Otros destinos & 11,6 & 9,5 & $\mathbf{1 0 , 6}$ \\
\hline Total & $\mathbf{1 0 0 , 0}$ & $\mathbf{1 0 0 , 0}$ & $\mathbf{1 0 0 , 0}$ \\
\hline
\end{tabular}

Fuente: Elaboración propia a partir de los datos de la encuesta.

Dicha reinversión fortalece el vínculo de estas entidades con el territorio, elevado ya de por sí, merced al origen local de la mayoría de empresarios y trabajadores y al carácter de la zona de asentamiento como principal punto de venta para casi un tercio de las empresas; cifra que alcanza casi el 58,6\% si se incorpora la provincia (Cuadro 13), concentrando ambos ámbitos de mercado el $63 \%$ de las ventas. La mayor amplitud de mercado se registra en los C.E.E. En todo caso, el peso de la actividad exportadora sobre la facturación total es muy reducido.

\section{Cuadro 13}

Ámbitos de mercado (\%)

\begin{tabular}{|l|rrr|r|}
\hline \multicolumn{1}{|c|}{ Ámbito de mercado } & Cooperativas & $\begin{array}{c}\text { Sociedades } \\
\text { Laborales }\end{array}$ & $\begin{array}{c}\text { Centros } \\
\text { Esp. Empleo }\end{array}$ & Total \\
\hline Local & 34,6 & 34,3 & 17,3 & $\mathbf{3 2 , 9}$ \\
Provincial & 22,6 & 31,5 & 14,4 & $\mathbf{2 5 , 7}$ \\
Regional & 21,7 & 23,0 & 28,8 & $\mathbf{2 2 , 9}$ \\
Nacional & 12,0 & 8,5 & 14,4 & $\mathbf{1 0 , 7}$ \\
Unión Europea & 7,4 & 2,8 & 23,1 & $\mathbf{6 , 8}$ \\
Resto del mundo & 1,6 & 0,0 & 1,9 & $\mathbf{1 , 0}$ \\
\hline Total & $\mathbf{1 0 0 , 0}$ & $\mathbf{1 0 0 , 0}$ & $\mathbf{1 0 0 , 0}$ & $\mathbf{1 0 0 , 0}$ \\
\hline \% Exportación/volumen de ventas & 3,3 & 1,2 & 0,5 & $\mathbf{2 , 1}$ \\
\hline
\end{tabular}

Fuente: Elaboración propia a partir de los datos de la encuesta.

La incidencia sobre el territorio resulta, en cualquier caso, ampliamente variada, si se considera la distribución municipal de la población total de empresas de la Economía Social de Castilla y León. Éstas se hallan ubicadas en poco más de 600 municipios, que si bien aglutinan el $84 \%$ de la población y el $87 \%$ de la ocupación regional, tan sólo suponen el $27 \%$ de los 2.248 municipios de la región. La dimensión rural de dicha proyección territorial se concreta en el 
hecho de que de esos 614 municipios con presencia de la Economía Social de mercado, el $96 \%$ son menores de 10.000 habitantes y el $80,4 \%$ menores de 2.000 , aglutinando, respectivamente, el $47,6 \%$ y el $30 \%$ del número de unidades productivas. A escala intraprovincial, estas últimas cifras se elevan por encima del $60 \%$ en Ávila, Soria, Segovia y Palencia, para las localidades con menos de 10.000 habitantes, y por encima del $40 \%$ en las dos primeras provincias y la de Zamora, para las inferiores a 2.000. A escala interprovincial, las que mayor peso empresarial tienen en la categoría de municipios netamente rurales (por debajo de 2.000 habitantes) son Salamanca y León (que reúnen conjuntamente un tercio de las unidades productivas); en el grupo de localidades menores de 10.000 destaca Salamanca (particularmente entre en las menores de 1.000), seguida de Burgos (ambas concentran el 38\% del total de empresas).

Examinando con mayor detalle la distribución intermunicipal de las empresas de Economía Social en Castilla y León (Cuadro 14) se deduce lo siguiente:

a) Que las localidades mayores de 30.000 habitantes - las capitales de provincia más Ponferrada, Miranda de Ebro y Aranda de Duero (el 2\% de los municipios con presencia de las empresas de Economía Social, y casi el $60 \%$ de la población y de la ocupación del universo considerado) reúnen conjuntamente el $46,2 \%$ del número total de empresas. Les sigue en importancia el colectivo municipal más numeroso, el de las localidades menores de 500 habitantes (41,5\% del total), - donde se ubica el $12,4 \%$ de las entidades, cifra que asciende al $20,9 \%$ considerando los municipios menores de 1.000 habitantes.

b) El primer grupo domina todos los sectores (especialmente en el sector servicios), salvo la agricultura, donde sobresale el segundo bloque (tanto en empresas agrarias de explotación común (Código 1) como en las dedicadas a la comercialización al por mayor de productos agrarios (Código 511). En la actividad forestal (Código 2) despunta, en cambio, el grupo de entre 1.000 y 5.000 habitantes.

c) Por subsectores, fuera del primer bloque municipal mencionado, destacan: la industria agroalimentaria (Código 15), predominante en los municipios menores de 500 habitante; los sectores textil-confección (Código 17/18), química (Código 24), material de transporte (Código 3435), telecomunicaciones (Código 64) y alquileres (Código 74), en aquéllos de entre 2001 y 5000; la industria maderera en el grupo de 1.001 a 2.000; y otros servicios como actividades asociativas (Código 91) (5011000), de transporte terrestre (Código 60) (10.001-30.000) y recreativas, culturales y deportivas (Código 92) (5.001-10.000). 
Cuadro 14

Distribución intermunicipal de las empresas de Economía Social CNAE-93

\begin{tabular}{|c|c|c|c|c|c|c|c|c|c|}
\hline$N^{0}$ habitantes & $<500$ & $\begin{array}{l}501- \\
1000 \\
\end{array}$ & $\begin{array}{l}1001- \\
2000\end{array}$ & $\begin{array}{l}2001- \\
5000\end{array}$ & $\begin{array}{l}5001- \\
10000 \\
\end{array}$ & $\begin{array}{l}10001- \\
30000\end{array}$ & $\begin{array}{l}30001- \\
50000 \\
\end{array}$ & capitales & Total \\
\hline \multirow{3}{*}{$\begin{array}{l}\text { Población } \\
\text { Ocupados } \\
\text { Localidad }\end{array}$} & 2,98 & 4,49 & 6,82 & 9,52 & 9,21 & 9,00 & 6,47 & 51,49 & 100,00 \\
\hline & 2,85 & 4,20 & 6,42 & 11,60 & 8,54 & 8,26 & 6,15 & 51,99 & 100,00 \\
\hline & 41,53 & 22,15 & 16,78 & 10,75 & 4,89 & 1,95 & 0,49 & 1,47 & 100,00 \\
\hline 511 & 28,64 & 15,53 & 15,53 & 12,14 & 6,80 & 2,43 & 3,40 & 15,53 & 100,00 \\
\hline 1 & 45,90 & 23,93 & 12,46 & 6,89 & 4,26 & 0,98 & 0,66 & 4,92 & 100,00 \\
\hline 2 & 11,76 & 11,76 & 35,29 & 23,53 & 0,00 & 0,00 & 0,00 & 17,65 & 100,00 \\
\hline Agricultura & 38,07 & 20,27 & 14,39 & 9,47 & 5,11 & 1,52 & 1,70 & 9,47 & 100,00 \\
\hline 15 & 24,85 & 13,02 & 13,61 & 14,79 & 10,65 & 4,14 & 3,55 & 15,38 & 100,00 \\
\hline $17 / 18$ & 11,76 & 16,47 & 15,29 & 22,35 & 5,88 & 9,41 & 1,18 & 17,65 & 100,00 \\
\hline 19 & 0,00 & 0,00 & 0,00 & 0,00 & 100,00 & 0,00 & 0,00 & 0,00 & 100,00 \\
\hline 20 & 10,53 & 15,79 & 21,05 & 13,16 & 13,16 & 0,00 & 5,26 & 21,05 & 100,00 \\
\hline $21-22$ & 0,00 & 0,00 & 12,77 & 10,64 & 10,64 & 2,13 & 4,26 & 59,57 & 100,00 \\
\hline 24 & 0,00 & 0,00 & 0,00 & 60,00 & 0,00 & 0,00 & 40,00 & 0,00 & 100,00 \\
\hline 25 & 0,00 & 0,00 & 0,00 & 0,00 & 0,00 & 0,00 & 33,33 & 66,67 & 100,00 \\
\hline 26 & 5,26 & 21,05 & 15,79 & 15,79 & 5,26 & 10,53 & 5,26 & 21,05 & 100,00 \\
\hline $27 / 28$ & 5,49 & 9,89 & 6,59 & 14,29 & 12,09 & 8,79 & 17,58 & 25,27 & 100,00 \\
\hline 29 & 0,00 & 17,65 & 5,88 & 5,88 & 11,76 & 0,00 & 5,88 & 52,94 & 100,00 \\
\hline $31-33$ & 0,00 & 0,00 & 7,69 & 7,69 & 15,38 & 0,00 & 0,00 & 69,23 & 100,00 \\
\hline $34-35$ & 14,29 & 14,29 & 0,00 & 28,57 & 14,29 & 14,29 & 0,00 & 14,29 & 100,00 \\
\hline 36 & 6,49 & 10,39 & 16,88 & 11,69 & 16,88 & 16,88 & 2,60 & 18,18 & 100,00 \\
\hline Industria & 11,83 & 11,65 & 12,87 & 14,96 & 11,13 & 6,96 & 6,09 & 24,52 & 100,00 \\
\hline Construcción & 4,96 & 5,79 & 8,68 & 17,36 & 7,85 & 10,33 & 10,74 & 34,30 & 100,00 \\
\hline 50 & 3,92 & 2,94 & 7,84 & 9,80 & 7,84 & 9,80 & 12,75 & 45,10 & 100,00 \\
\hline 51 & 3,95 & 3,39 & 8,47 & 11,86 & 7,91 & 5,65 & 7,34 & 51,41 & 100,00 \\
\hline 52 & 2,52 & 0,72 & 3,24 & 6,83 & 5,04 & 9,71 & 5,76 & 66,19 & 100,00 \\
\hline 55 & 7,58 & 6,82 & 9,85 & 7,58 & 7,58 & 6,82 & 3,79 & 50,00 & 100,00 \\
\hline 60 & 0,00 & 13,51 & 10,81 & 5,41 & 5,41 & 16,22 & 5,41 & 43,24 & 100,00 \\
\hline 63 & 0,00 & 0,00 & 0,00 & 4,55 & 9,09 & 0,00 & 0,00 & 86,36 & 100,00 \\
\hline 64 & 0,00 & 0,00 & 0,00 & 20,00 & 10,00 & 0,00 & 0,00 & 70,00 & 100,00 \\
\hline $65-67$ & 3,23 & 0,00 & 3,23 & 0,00 & 9,68 & 0,00 & 0,00 & 83,87 & 100,00 \\
\hline 70 & 0,00 & 2,67 & 2,67 & 1,33 & 1,33 & 0,00 & 4,00 & 88,00 & 100,00 \\
\hline 71 & 0,00 & 0,00 & 0,00 & 25,00 & 0,00 & 0,00 & 0,00 & 75,00 & 100,00 \\
\hline 72 & 2,50 & 0,00 & 5,00 & 7,50 & 2,50 & 5,00 & 10,00 & 67,50 & 100,00 \\
\hline 74 & 3,00 & 1,50 & 4,00 & 4,50 & 6,00 & 7,00 & 7,50 & 66,50 & 100,00 \\
\hline 80 & 4,00 & 0,00 & 0,00 & 4,00 & 12,00 & 0,00 & 0,00 & 80,00 & 100,00 \\
\hline 85 & 1,72 & 1,72 & 3,45 & 13,79 & 3,45 & 5,17 & 8,62 & 62,07 & 100,00 \\
\hline 91 & 0,00 & 50,00 & 0,00 & 0,00 & 0,00 & 0,00 & 0,00 & 50,00 & 100,00 \\
\hline 92 & 4,76 & 4,76 & 4,76 & 14,29 & 23,81 & 14,29 & 9,52 & 23,81 & 100,00 \\
\hline 93 & 2,56 & 0,00 & 0,00 & 2,56 & 0,00 & 12,82 & 12,82 & 69,23 & 100,00 \\
\hline Servicios & 3,19 & 2,63 & 5,19 & 7,34 & 6,23 & 7,10 & 6,62 & 61,69 & 100,00 \\
\hline TOTAL & 12,36 & 8,51 & 9,08 & 10,39 & 7,24 & 6,24 & 5,89 & 40,30 & 100,00 \\
\hline
\end{tabular}

Fuente: Elaboración propia a partir de los datos de la encuesta. 
El Cuadro 15 viene a reforzar buena parte de las afirmaciones anteriores. Así, la actividad agraria viene a caracterizar el tejido productivo en Economía Social de los municipios eminentemente rurales, los menores de 2.000 habitantes (particularmente en los de menos de 500, donde un 62,6\% de sus empresas está vinculado al sector primario). Algo similar ocurre con actividades agroindustriales como la industria agroalimentaria $\mathrm{y}$, en menor medida, la maderera (ésta última en los municipios de entre 501 y 2.000 habitantes).

Otras ramas manufactureras con peso en las economías locales son la de textil-confección (501-5.000 habitantes), la del mueble (Código 36) (5.00130.000 habitantes) y la de transformados metálicos (Código 27/28) que, junto a la construcción alcanza las cifras más relevantes en la Economía Social de los municipios intermedios (de más de 2.000 habitantes no capitales de provincia). Las actividades terciarias destacan con diferencia en los municipios mayores de 10.000 habitantes, figurando con los porcentajes más destacados en todas las categorías municipales el comercio (Código 51/52), especialmente al por menor (Código 52), otros servicios (limpieza, servicios profesionales,...) (Código 74) y la hostelería (Código 55).

Aunque la ratio "empresas de Economía Social por municipio" resulta muy superior en las capitales de provincia y localidades mayores de 30.000 habitantes, su importancia se ve obviamente diluida en su más amplio tejido económico. De hecho, es el paisaje productivo de los municipios rurales el que se ve más intensamente afectado por la Economía Social, como revelan los mayores coeficientes de empresas por habitante y por ocupado en los municipios con menos de 2.000 habitantes (y particularmente relevantes en provincias como Salamanca y Soria, seguidas de Segovia, Zamora y Burgos). Algunas localidades mayores de 2.000 pero de marcado carácter rural, también muestran ratios dignas de atención, como Vitigudino, Paredes de Nava, Peñaranda de Bracamonte, Ágreda y Almazán; todas ellas presentan una cierta entidad como plataformas para la industrialización local. Con todo, donde se detecta la más peculiar correlación entre el fenómeno del desarrollo local/rural y la Economía Social es en los SPL de Medina del Campo, Tierra de Pinares (con Covaleda y Duruelo de la Sierra en cabeza), Íscar o la Ribera del Duero burgalesa, con un significativo número de cooperativas y sociedades laborales centradas en la especialización productiva típica a escala local.

El análisis realizado viene, en definitiva, a poner de manifiesto una apreciable presencia significativa de las actividades de cooperativas y sociedades laborales en las zonas rurales de Castilla y León, en consonancia con las sinergias establecidas a nivel teórico entre el modelo de desarrollo local/rural y las potencialidades de la Economía Social que fueron previamente identificadas. 


\section{Cuadro 15}

Distribución intramunicipal de las empresas de Economía Social CNAE-93

\begin{tabular}{|c|c|c|c|c|c|c|c|c|c|}
\hline$N^{0}$ habitantes & $<500$ & $\begin{array}{l}501- \\
1000 \\
\end{array}$ & $\begin{array}{l}1001- \\
2000\end{array}$ & $\begin{array}{c}2001- \\
5000\end{array}$ & $\begin{array}{l}5001- \\
10000 \\
\end{array}$ & $\begin{array}{l}10001- \\
30000\end{array}$ & $\begin{array}{l}30001- \\
50000\end{array}$ & capitales & Total \\
\hline \multirow{3}{*}{$\begin{array}{l}\text { Empr/pobl. } \\
\text { Empr/ocup. } \\
\text { Empr/munic. }\end{array}$} & 0,51 & 0,23 & 0,16 & 0,13 & 0,10 & 0,09 & 0,11 & 0,10 & 0,12 \\
\hline & 1,40 & 0,66 & 0,46 & 0,29 & 0,27 & 0,24 & 0,31 & 0,25 & 0,32 \\
\hline & 1,26 & 1,63 & 2,29 & 4,09 & 6,27 & 13,50 & 51,00 & 116,33 & 4,23 \\
\hline 511 & 18,38 & 14,48 & 13,56 & 9,26 & 7,45 & 3,09 & 4,58 & 3,06 & 7,93 \\
\hline 1 & 43,61 & 33,03 & 16,10 & 7,78 & 6,91 & 1,85 & 1,31 & 1,43 & 11,74 \\
\hline 2 & 0,62 & 0,90 & 2,54 & 1,48 & 0,00 & 0,00 & 0,00 & 0,29 & 0,65 \\
\hline Agricultura & 62,62 & 48,42 & 32,20 & 18,52 & 14,36 & 4,94 & 5,88 & 4,78 & 20,32 \\
\hline 15 & 13,08 & 9,95 & 9,75 & 9,26 & 9,57 & 4,32 & 3,92 & 2,48 & 6,51 \\
\hline $17 / 18$ & 3,12 & 6,33 & 5,51 & 7,04 & 2,66 & 4,94 & 0,65 & 1,43 & 3,27 \\
\hline 19 & 0,00 & 0,00 & 0,00 & 0,00 & 0,53 & 0,00 & 0,00 & 0,00 & 0,04 \\
\hline 20 & 1,25 & 2,71 & 3,39 & 1,85 & 2,66 & 0,00 & 1,31 & 0,76 & 1,46 \\
\hline $21-22$ & 0,00 & 0,00 & 2,54 & 1,85 & 2,66 & 0,62 & 1,31 & 2,67 & 1,81 \\
\hline 24 & 0,00 & 0,00 & 0,00 & 1,11 & 0,00 & 0,00 & 1,31 & 0,00 & 0,19 \\
\hline 25 & 0,00 & 0,00 & 0,00 & 0,00 & 0,00 & 0,00 & 1,31 & 0,38 & 0,23 \\
\hline 26 & 0,31 & 1,81 & 1,27 & 1,11 & 0,53 & 1,23 & 0,65 & 0,38 & 0,73 \\
\hline $27 / 28$ & 1,56 & 4,07 & 2,54 & 4,81 & 5,85 & 4,94 & 10,46 & 2,20 & 3,50 \\
\hline 29 & 0,00 & 1,36 & 0,42 & 0,37 & 1,06 & 0,00 & 0,65 & 0,86 & 0,65 \\
\hline $31-33$ & 0,00 & 0,00 & 0,42 & 0,37 & 1,06 & 0,00 & 0,00 & 0,86 & 0,50 \\
\hline $34-35$ & 0,31 & 0,45 & 0,00 & 0,74 & 0,53 & 0,62 & 0,00 & 0,10 & 0,27 \\
\hline 36 & 1,56 & 3,62 & 5,51 & 3,33 & 6,91 & 8,02 & 1,31 & 1,34 & 2,96 \\
\hline Industria & 21,18 & 30,32 & 31,36 & 31,85 & 34,04 & 24,69 & 22,88 & 13,47 & 22,13 \\
\hline Construcción & 3,74 & 6,33 & 8,90 & 15,56 & 10,11 & 15,43 & 16,99 & 7,93 & 9,31 \\
\hline 50 & 1,25 & 1,36 & 3,39 & 3,70 & 4,26 & 6,17 & 8,50 & 4,39 & 3,93 \\
\hline 51 & 2,18 & 2,71 & 6,36 & 7,78 & 7,45 & 6,17 & 8,50 & 8,69 & 6,81 \\
\hline 52 & 2,18 & 0,90 & 3,81 & 7,04 & 7,45 & 16,67 & 10,46 & 17,57 & 10,70 \\
\hline 55 & 3,12 & 4,07 & 5,51 & 3,70 & 5,32 & 5,56 & 3,27 & 6,30 & 5,08 \\
\hline 60 & 0,00 & 2,26 & 1,69 & 0,74 & 1,06 & 3,70 & 1,31 & 1,53 & 1,42 \\
\hline 63 & 0,00 & 0,00 & 0,00 & 0,37 & 1,06 & 0,00 & 0,00 & 1,81 & 0,85 \\
\hline 64 & 0,00 & 0,00 & 0,00 & 0,74 & 0,53 & 0,00 & 0,00 & 0,67 & 0,38 \\
\hline $65-67$ & 0,31 & 0,00 & 0,42 & 0,00 & 1,60 & 0,00 & 0,00 & 2,48 & 1,19 \\
\hline 70 & 0,00 & 0,90 & 0,85 & 0,37 & 0,53 & 0,00 & 1,96 & 6,30 & 2,89 \\
\hline 71 & 0,00 & 0,00 & 0,00 & 0,37 & 0,00 & 0,00 & 0,00 & 0,29 & 0,15 \\
\hline 72 & 0,31 & 0,00 & 0,85 & 1,11 & 0,53 & 1,23 & 2,61 & 2,58 & 1,54 \\
\hline 74 & 1,87 & 1,36 & 3,39 & 3,33 & 6,38 & 8,64 & 9,80 & 12,70 & 7,70 \\
\hline 80 & 0,31 & 0,00 & 0,00 & 0,37 & 1,60 & 0,00 & 0,00 & 1,91 & 0,96 \\
\hline 85 & 0,31 & 0,45 & 0,85 & 2,96 & 1,06 & 1,85 & 3,27 & 3,44 & 2,23 \\
\hline 91 & 0,00 & 0,45 & 0,00 & 0,00 & 0,00 & 0,00 & 0,00 & 0,10 & 0,08 \\
\hline 92 & 0,31 & 0,45 & 0,42 & 1,11 & 2,66 & 1,85 & 1,31 & 0,48 & 0,81 \\
\hline 93 & 0,31 & 0,00 & 0,00 & 0,37 & 0,00 & 3,09 & 3,27 & 2,58 & 1,50 \\
\hline Servicios & 12,46 & 14,93 & 27,54 & 34,07 & 41,49 & 54,94 & 54,25 & 73,83 & 48,23 \\
\hline TOTAL & 100,00 & 100,00 & 100,00 & 100,00 & 100,00 & 100,00 & 100,00 & 100,00 & 100,00 \\
\hline
\end{tabular}

Fuente: Elaboración propia a partir de los datos de la encuesta. 


\section{CONCLUSIONES}

Las entidades que configuran la llamada Economía Social desempeñan una serie de funciones que - más allá de su genérico impulso hacia una sociedad más plural, participativa, democrática y solidaria - muestran su gran trascendencia económica. Así, cabe destacar su contribución a una mayor equidad en el reparto de la renta y la riqueza, su acción correctora de los desequilibrios en el mercado laboral, su vinculación a actividades productivas ligadas a las necesidades sociales, su fomento de la estabilidad macroeconómica y el desarrollo sostenible, así como su capacidad para estimular procesos de desarrollo local/rural, fenómeno con el cual presentan considerables sinergias. La Economía Social puede llegar a desempeñar un papel clave en el desarrollo local/rural, cuyo concurso se pone de manifiesto, fundamentalmente, a través de la tendencia al aprovechamiento de los factores endógenos; la generación de empleos estables y de calidad; la participación activa de la población y los agentes sociales; y la fijación del capital humano al territorio. Todos ellos, factores de especial importancia estratégica dentro del contexto de los procesos de desarrollo económico y social que operan en el medio rural. Así, el ámbito rural presenta características muy ventajosas para el desarrollo de iniciativas de Economía Social, tales como: unas estrechas relaciones interpersonales; una tradición de solidaridad y hospitalidad; una gran sensibilidad ante su riqueza patrimonial; una fuerte relación con el medio natural; un intenso sentimiento de identidad y de preservación de la cultura rural. Sin embargo, existen también ciertos problemas comunes a las zonas rurales que condicionan su desarrollo socioeconómico, como son: su aislamiento territorial; el reducido tamaño de su mercado local; la insuficiencia de recursos humanos; la tendencia a la emigración de las personas más dinámicas ante la falta de oportunidades y empleo; las carencias en materia de infraestructuras económicas y de equipamientos sociales; el acceso deficiente a la información y a las tecnologías para aprovechar y transformar sus recursos endógenos; o la insuficiencia de recursos financieros para el adecuado impulso de iniciativas emprendedoras. Pese a todo, la respuesta de la Economía Social ha sido positiva, sosteniendo y promoviendo procesos de desarrollo local generadores de renta y empleo en las zonas rurales.

En lo que se refiere a la proyección territorial del desarrollo local/rural en España (focalizada mayormente en torno a la industria), ésta ha sido mucho más intensa que en la Comunidad Autónoma de Castilla y León. Dicha debilidad guarda, al menos de manera indirecta, una cierta correlación con el menor peso de la Economía Social - en particular del subsector de mercado - en el tejido productivo de la región, dando como resultado un impacto territorial más limitado y modesto. Esto no significa que la estrategia del desarrollo local no revista interés para Castilla y León, en especial para su medio rural; ni tampoco 
que la Economía Social no pueda jugar un papel más importante en el futuro, dado el amplio margen existente para su expansión hasta alcanzar la media nacional. De hecho, el análisis del subsector de mercado de la Economía Social revela la presencia de importantes elementos de convergencia con el desarrollo local/rural: base en la PYME, autoempleo y estabilidad laboral; uso del potencial endógeno; valores democráticos; orientación hacia el largo plazo y hacia la sostenibilidad; nuevos yacimientos de empleo intensivos en trabajo (asistencia a personas dependientes, enseñanza, servicios de limpieza, agricultura ecológica, turismo rural y agroturismo, inserción laboral y lucha contra la exclusión social); vinculación al territorio; apertura al complemento de la iniciativa pública, etc. Dicho subsector de mercado presenta, no obstante, algunas debilidades que limitan su potencial como vehículo para el desarrollo en el medio rural, como son el minifundismo empresarial, el modesto nivel de formación de la plantilla de las empresas analizadas, del que se derivan importantes necesidades formativas en materia técnica en directivos y trabajadores, y la infrecuente tendencia a la cooperación (ligada a una mentalidad marcadamente individualista), que se traduce en una escasa importancia del asociacionismo.

El esfuerzo en los frentes formativo, tecnológico y cooperativo resulta, por tanto, crucial al objeto de fortalecer la dimensión y el papel de la Economía Social en el ámbito rural de la región cara al futuro. Esta labor no sólo compete a las organizaciones de la Economía Social, sino también a los poderes públicos, a través de actuaciones orientadas a potenciar su constitución; mejorar sus mecanismos de financiación y demás servicios de apoyo; fomentar la apuesta por las nuevas tecnologías y la implantación de una cultura de la innovación y de la calidad y excelencia empresarial; aumentar su nivel de capital humano; e impulsar la cooperación e integración interempresarial. En este contexto, pueden desempeñar funciones relevantes en las zonas rurales figuras como los agentes de empleo y desarrollo local y, sobre todo, los llamados Grupos de Acción Local (GAL), los cuales, como asociaciones sin ánimo de lucro, constituyen una pieza fundamental de la Economía Social en España. La actuación de estos GAL - 44 en Castilla y León - en tanto que gestores (en el escenario de la actual política territorial europea) de un amplio volumen de recursos financieros con fines de desarrollo local y como exponentes de partenariado público-privado viene configurándose, desde la implantación de la Iniciativa Europea LEADER, como un elemento clave para el progreso económico y social del medio rural de Castilla y León. En cualquier caso, la crisis financiero-económica ha supuesto un cambio radical en la situación y perspectivas de la Economía Social castellana y leonesa, cuyas repercusiones están condicionando su potencial como agente al servicio del desarrollo local/rural. Con todo, en este nuevo escenario, las entidades de la Economía Social están respondiendo con estrategias adaptativas de 
supervivencia diferenciadas que les está permitiendo resistir mejor que otras alternativas productivas las consecuencias de la actual crisis.

\section{REFERENCIAS BIBLIOGRÁFICAS}

BAREA, J. Y MONZÓN, J.L., (dir.) (2002): La Economía Social en España en el año 2000. CIRIEC-España, Valencia.

BECATTINI, G., COSTA, M.T. Y TRULLÉN, J. (coord.) (2002): Desarrollo local: teorías y estrategias. Civitas, Madrid.

BEL, P. Y CABALEIRO, M.J. (2002): "La sociedad cooperativa: fórmula empresarial idónea para el desarrollo rural endógeno y sostenible". Revista Española de Estudios Agrosociales y Pesqueros, n 194, pp. 9-26 .

BENKO, G. Y LIPIETZ, A. (eds.) (1992): Les régions qui gagnent. Districts et réseaux: les nouveaux paradigmes de la géographie économique. PUF, París.

BUENDÍA, I. Y GARCÍA, J.V. (coord.) (2003): Cooperativismo y desarrollo local. Centro de Estudios Ramón Areces-Fundación Luis Vives, Madrid.

CASTILLO, J. DEL et al. (1994), BARROETA, B., BAYÓN, M.M. Y CORDERO, E. (1994): Manual de desarrollo local. Gobierno Vasco, Departamento de Economía y Hacienda, Bilbao.

CHAVES, R. (2006): "La Economía Social en España: concepto, agentes y políticas públicas". En Pérez de Uralde, J.Ma (coord.): La Economía Social en Iberoamérica. Fundación Iberoamericana de la Economía Social, Madrid, pp. 215-269.

CHAVES, R. Y MONZÓN, J.L. (2003): "La Economía Social y la Política Económica”. En Jordán Galduf, J.M ${ }^{a}$ et al. (coord.): Política Económica: fundamentos, objetivos e instrumentos, Tirant lo Blanch, Valencia, pp. 363389.

CLEMENTE, J., DÍAZ, M. Y MARCUELLO, C. (2009): "Sociedades cooperativas y sociedades laborales en España: estudio de su contribución a la creación de empleo y al crecimiento económico". REVESCO, Revista de Estudios Cooperativos, $\mathrm{n}^{\circ}$ 98, pp. 35-69.

COQUE, J. (2003): "El desarrollo local sobre bases cooperativas. Valorización de los recursos locales y creación de redes". En Buendía, I. y García, J.V. (coord.) (2003): Cooperativismo y desarrollo local. C.E. R. Areces-F. L. Vives, Madrid, pp. 261-299.

DE PABLO, J. Y URIBE, J. (2009): "Emprendimiento de la economia social y desarrollo local: la promoción de incubadoras de empresas de economía social en Andalucía". CIRIEC-España, Revista de Economía Pública, Social y Cooperativa, $n^{\circ} 64$, pp. 5-33. 
DEMOUSTIER, D. (dir) (2005): Économie sociale et développement local. L'Harmattan, Paris.

FERNÁNDEZ, J.E. Y GÓMEZ, J:Ma (dir.) (2008): La economía social en Castilla y León. Estudio del Sector Empresarial. Sever-Cuesta Editores. Valladolid.

FERNÁNDEZ, J.E., GÓMEZ, J:Ma Y ROMÁN, A. (coord.) (2010): Estudios de Economía Social. Universidad de Valladolid. Valladolid.

GAROFOLI, G. Y MAZZONI, R. (1994): "I sistemi produttivi locali: un'introduzione". En Garofoli, G. y Mazzoni, R. (coords.): Sistemi produttivi locali: struttura e trasformazione, Franco Angeli, Milán, pp. 7-24.

GÓMEZ, J.M ${ }^{a}$ Y FERNÁNDEZ, J.E. (2008): "La economía social en el desarrollo económico regional: un análisis del subsector de mercado en Castilla y León”. Estudios de Economía Aplicada, n² 26-1, abril 2008, pp. 253-274.

GÓMEZ, J.Ma Y ROMÁN, A. (2005): "La economía social y su contribución a la promoción del desarrollo local y regional". RUCT, Revista Universitaria de Ciencias del Trabajo, ${ }^{\circ}$ 6, pp. 727-753.

GÓMEZ, J.Ma , ROMÁN, A. Y ROJO, C. (2010): "Las dimensiones de la calidad del empleo en la Economía Social: un análisis de las sociedades laborales y los centros especiales de empleo en Castilla y León". CIRIEC-España, Revista de Economía Pública, Social y Cooperativa, nº 67, pp. 45-74.

JUSTE, J.J. (2001): Desarrollo Local y Mercado Global: los sistemas productivos locales y la industria agroalimentaria en Castilla y León. Tesis Doctoral, Departamento de Economía Aplicada. Universidad de Valladolid.

JUSTE, J.J. et al. (2007): "Los sistemas productivos locales industriales en Castilla y León”. En Anales de Economía Aplicada 2007, ASEPELT-Delta publicaciones, Madrid, pp. 83-104.

JUSTE, J.J. (2010): "La Economía Social y el desarrollo local. Fundamentos y elementos de conexión". En Fernández, J.E., Gómez, J.M ${ }^{a}$ y Román, A. (coord.) (2010): Estudios de Economía Social. Universidad de Valladolid. Valladolid, pp. 283-324.

LÉVESQUE, B. (1999): "Développement local et économie sociale: éléments incontournables du nouvel environnement". Économie et Solidarités, Vol. 30, no 1, pp. 111-126.

MARTIGNETTI, L. (2002): La importancia de la economía social para el desarrollo local y territorial. REVES, Red Europea de las ciudades y Regiones de la Economía Social. Bruselas.

MONTERO, A. (1997): "Cooperativismo y desarrollo rural". REVESCO, 63, pp. 63-77.

MOZAS, A. Y BERNAL, E. (2006): "Desarrollo territorial y economía social". CIRIEC-España, Revista de Economía Pública, Social y Cooperativa, $n^{\circ} 55$, pp. $125-140$. 
RICO, M. Y GÓMEZ, J.Mª (2009a): "La contribución de la mujer en la economía rural de Castilla y León". Revista de Economía Agraria y Recursos Naturales, $n^{\circ} 9$ (2), 2009, pp. 51-77.

RICO, M. Y GÓMEZ, J.Ma (2009b): "La contribución económica de la mujer al desarrollo del medio rural de Castilla y León: un análisis aplicado al turismo rural". Anales de Estudios Económicos y Empresariales, n 19, pp. 257-296.

SALINAS, F., HERRÁN, J.M ${ }^{a}$ Y ALBARRÁN (coord.)(2005): "Desarrollo rural y economía social". Universidad Católica de Ávila. Ávila.

SANCHIS, J.R. Y CAMPOS, V. (2005): "Inserción sociolaboral, economía social y desarrollo local. Estudio empírico sobre la realidad actual del agente de empleo y desarrollo local en España". CIRIEC-España, Revista de Economía Pública, Social y Cooperativa, n 52, pp. 279-306.

TOSCANO, F. (2000): "Desarrollo local y Economía Social". En Pérez Ramírez, B. y Carrillo Benito, E.: Desarrollo local: Manual de uso, Esic Editorial/Federación Andaluza de Municipios y Provincias, Madrid, pp. 445470.

TREMBLAY, D. et al (dir) (2002): Développement local, économie sociale et démocratie. Pratiques et politiques sociales et économiques. Presses de l'Université du Québec, Québec.

VÁZQUEZ BARQUERO, A. (1988): Desarrollo local: Una estrategia de creación de empleo. Pirámide, Madrid.

VÁZQUEZ BARQUERO, A. (2005): Las nuevas fuerzas del desarrollo. Pirámide, Madrid. 
